\title{
Ceramide Kinase Regulates TNF-a-induced Immune Responses in Human Monocytic Cells
}

\section{Fatema Al-Rashed}

Dasman Diabetes Institute

\section{Zunair Ahmad}

Royal College of Surgeons in Ireland - Bahrain

\section{Ashley J Snider}

University of Arizona

\section{Reeby Thomas}

Dasman Diabetes Institute

\section{Shihab Kochumon}

Dasman Diabetes Institute

\section{Motasem Melhem}

Dasman Diabetes Institute

\section{Sardar Sindhu}

Dasman Diabetes Institute

\section{Lina M Obeid}

Stony Brook University

\section{Fahd Al-Mulla}

Dasman Diabetes Institute

\section{Yusuf A Hannun}

Stony Brook University

Rasheed Ahmad ( $\nabla$ rasheed.ahmad@dasmaninstitute.org)

Immunology \& Immunology Department, Dasman Diabetes Institute, Al-Soor Street, Kuwait, P.O. Box 1180 Dasman, 15462 Kuwait

\section{Research Article}

Keywords: CERK, TNF-a, CD11c, HLA-DR, Monocytes, inflammation

Posted Date: January 28th, 2021

DOI: https://doi.org/10.21203/rs.3.rs-146950/v1

License: (9) (1) This work is licensed under a Creative Commons Attribution 4.0 International License. 
Version of Record: A version of this preprint was published at Scientific Reports on April 15th, 2021. See the published version at https://doi.org/10.1038/s41598-021-87795-7. 
Title:

Authors:

Affiliations:

Running title:

*Correspondence:

Key words:
Ceramide Kinase Regulates TNF- $\alpha$-Induced Immune Responses in Human Monocytic Cells

Fatema Al-Rashed ${ }^{1}$, Zunair Ahmad ${ }^{2}$, Ashley J. Snider ${ }^{3,4}$ Reeby Thomas ${ }^{1}$, Shihab Kochumon ${ }^{1}$, Motasem Melhem ${ }^{5}$, Sardar Sindhu ${ }^{6}$, Lina M. Obeid ${ }^{3}$, Fahd Al-Mulla $^{5}$, Yusuf A. Hannun ${ }^{3}$, Rasheed Ahmad ${ }^{1 *}$

${ }^{1}$ Immunology \& Microbiology Department, Dasman Diabetes Institute, Kuwait; ${ }^{2}$ Royal College of Surgeons in Ireland -Bahrain; ${ }^{3}$ Stony Brook Cancer Center and Department of Medicine, Stony Brook University, Stony Brook, NY 11794, USA;

${ }^{4}$ Department of Nutritional Sciences, College of Agriculture and Life Sciences, University of Arizona, Tucson, AZ 85721, USA; ${ }^{5}$ Genetics and Bioinformatics Department, Dasman Diabetes Institute, Kuwait; ${ }^{6}$ Animal and Imaging Core Facility, Dasman Diabetes Institute, Kuwait.

TNF- $\alpha$ activates monocytes/macrophages via CERK

Rasheed Ahmad Ph.D., Immunology \& Immunology Department, Dasman Diabetes Institute, Al-Soor Street, Kuwait, P.O. Box 1180 Dasman, 15462 Kuwait. Phone: 96522242999 Ext. 4311; Fax: 9652249 2406; E-mail: rasheed.ahmad@dasmaninstitute.org

CERK, TNF- $\alpha$, CD11c, HLA-DR, Monocytes, inflammation 


\begin{abstract}
Ceramide kinase (CERK) phosphorylates ceramide to produce ceramide-1-phosphate (C1P), which is involved in the development of metabolic inflammation. TNF- $\alpha$ modulates inflammatory responses in monocytes associated with various inflammatory disorders; however, the underlying mechanisms remain not fully understood. Here, we investigated the role of CERK in TNF- $\alpha$-induced inflammatory responses in monocytes. Our results show that disruption of CERK activity in monocytes either by the chemical inhibitor NVP- 231 or by small interfering RNA (siRNA) results in the defective expression of inflammatory markers including CD11c, CD11b and HLA-DR in response to TNF- $\alpha$. Our data show that TNF- $\alpha$ upregulates ceramide phosphorylation. Inhibition of CERK in monocytes significantly reduced the secretion of IL-1 $\beta$ and MCP-1. Similar results were observed in CERK deficient cells. Phosphorylation of JNK, p38 and NF- $\mathrm{BB}$ resulting from TNF- $\alpha$ stimulation was reduced by inhibition of CERK. Additionally, NF-kB/AP-1 activity was suppressed by the inhibition of CERK. Clinically, obese individuals had higher levels of CERK expression in PBMCs compared to lean individuals, which correlated with TNF- $\alpha$ levels. Taken together, these results suggest that CERK plays a key role in regulating inflammatory responses in human monocytes during TNF- $\alpha$ stimulation. CERK may be a relevant target for developing novel therapies for chronic inflammatory diseases.
\end{abstract}




\section{INTRODUCTION}

Ceramide kinase (CERK) is an enzyme that regulates the phosphorylation of ceramide and produces ceramide-1-phosphate (C1P), a sphingolipid which is commonly implicated in inflammation. CERK is overexpressed in breast cancer and is associated with poor prognosis Moreover, CERK/C1P promote breast, lung and pancreatic cancers via cell growth, migration, survival, and invasion processes ${ }^{1}$. CERK deficiency reduced the expression of peroxisome proliferator-activated receptor gamma (PPAR $\gamma$ ) in adipocytes which resulted in defective adipogenesis ${ }^{2}$. Involvement of CERK in inflammation is well documented ${ }^{3,4}$. It was reported that the deficiency of CERK suppressed inflammation in adipose tissue through attenuating MCP-1/CCR2 signaling in infiltrated macrophages and improved insulin resistance which pinpointing CERK as a potential therapeutic target for the treatment of obesity and insulin resistance 5. Furthermore, CERK knockout mice expressed lower levels of MCP-1 which is a well-known inflammatory marker in the adipose tissue. Moreover, MCP-1-induced infiltration of macrophages into the adipose tissue was significantly reduced in CERK KO mice, suggesting that CERK deficiency could improve metabolic inflammation ${ }^{5}$

Obesity and metabolic syndrome are characterized by chronic low-grade inflammation mainly originating from the crosstalk between monocytes/macrophages and adipocytes in the adipose tissue. In obesity settings, monocytes exhibit an inflammatory phenotype associated with the increased expression of CD11b, CD11c and HLA-DR surface markers ${ }^{6,7}$ along with higher secretion of proinflammatory cytokines/chemokines such as TNF- $\alpha$, IL-6, IL-1 $\beta$, and MCP-1 ${ }^{6,8}$. TNF- $\alpha$ is a proinflammatory cytokine overexpressed in obese humans and rodents and has been identified as a key regulator of inflammation and insulin resistance ${ }^{9}$. TNF- $\alpha$ activates the immune cells, particularly monocytes and macrophages into a proinflammatory state ${ }^{6}$. However, the underlying mechanisms are still not clear. Since CERK is involved in metabolic inflammation, we investigated whether CERK regulated the phenotypic changes in monocytes induced by TNF- $\alpha$. We found that inhibition of CERK by either a specific chemical inhibitor or siRNA significantly blocked the TNF- $\alpha$-induced expression of inflammatory monocyte markers including 
CD11b, CD11c and HLA-DR. In parallel, inhibition of CERK suppresses the TNF- $\alpha$-mediated secretion of inflammatory cytokine/chemokine, such as IL-1 $\beta$ and MCP-1. Mechanistically, CERK inhibition decreased the TNF- $\alpha$-induced phosphorylation of JNK, p38 and NF- $\kappa$ B. As expected, we also found increased expression of CERK in PBMCs of obese individuals which correlated with TNF- $\alpha$ expression. Altogether, our data show an interesting novel role of CERK in TNF- $\alpha$-driven inflammation.

\section{MATERIALS AND METHODS}

All methods were performed in accordance with the relevant guidelines and regulations.

\section{Cell Culture}

Monocytes. Human monocytic THP-1 cells were purchased from American Type Culture Collection (ATCC) and grown in RPMI-1640 culture medium (Gibco, Life Technologies, Grand Island, USA) supplemented with 10\% fetal bovine serum (Gibco, Life Technologies, Grand Island, NY, USA), 2 mM glutamine (Gibco, Invitrogen, Grand Island, NY, USA), 1 mM sodium pyruvate, 10 mM HEPES, 100 ug/ml Normocin, $50 \mathrm{U} / \mathrm{ml}$ penicillin and $50 \mu \mathrm{g} / \mathrm{ml}$ streptomycin (P/S; (Gibco, Invitrogen, Grand Island, NY, USA). Cells were then incubated at $37^{\circ} \mathrm{C}$ (with humidity) in $5 \% \mathrm{CO}_{2}$. NF-kB reporter monocytic cells (THP-1-XBlue) stably expressing a secreted embryonic alkaline phosphatase (SEAP) reporter inducible by NF-אB were purchased from InvivoGen (InvivoGen, San Diego, CA, USA). -. THP-1-XBlue cells were cultured in complete RPMI medium with the addition of zeocin $(200 \mu \mathrm{g} / \mathrm{ml})$ (InvivoGen, San Diego, CA, USA). Prior to stimulation, monocytes were transferred to normal medium and plated in 12-well plates (Costar, Corning Incorporated, Corning, NY, USA) at $1 \times 10^{6}$ cells/well cell density unless indicated otherwise.

\section{PBMCs collection and monocyte purification}

Human peripheral blood $(30 \mathrm{ml})$ samples were collected from healthy volunteers in EDTA vacutainer tubes. All participants gave written informed consent, and studies were approved by the ethics committee of Dasman Diabetes Institute, Kuwait (04/07/2010; RA-2010-003). Physical characteristics of the study 
participants are shown in s Table 1. PBMCs were isolated by using Histo-Paque density gradient method as described ${ }^{10}$. PBMCs were plated in 6-well plates (Costar, Corning Incorporated, Corning, NY, USA) at $3 \times 10^{6}$ cells/well in starvation medium for 3 hours at $37^{\circ} \mathrm{C}$. Non-adhered cells were removed, and monocytes that have adhered to the plate were washed with culture media without serum and incubated for 24 hrs in RPMI with 2\% Fetal Bovine serum.

Table 1: Descriptive characteristics of the study population

\begin{tabular}{lllll}
$\begin{array}{c}\text { Physical } \\
\text { characteristics of subjects }\end{array}$ & $\begin{array}{l}\text { Lean } \\
(\mathrm{N}=9)\end{array}$ & $\begin{array}{l}\text { Overweight } \\
(\mathrm{N}=8)\end{array}$ & $\begin{array}{l}\text { Obese } \\
(\mathrm{N}=10)\end{array}$ & \begin{tabular}{l} 
P-value \\
\hline Age (years)
\end{tabular} \\
Weight (kg) & $39.2 \pm 11.1$ & $42.6 \pm 14.0$ & $46.1 \pm 12.3$ & 0.4744 \\
Height (cm) & $60.1 \pm 8.25$ & $74.4 \pm 9.88$ & $104 \pm 17$ & $<\mathbf{0 . 0 0 0 1}^{* * * *}$ \\
BMI (kg/m2) & $1.64 \pm 0.06$ & $1.62 \pm 0.12$ & $1.70 \pm 0.09$ & 0.1724 \\
Waist circumference(inch) & $78 \pm 3.6$ & $93.5 \pm 3.6$ & $115.27 \pm 13.9$ & $\mathbf{0 . 0 0 1 2}^{* *}$ \\
Hip circumference (inch) & $95.3 \pm 4.6$ & $107.5 \pm 5.91$ & $114.6 \pm 6.8$ & $\mathbf{0 . 0 0 2 5}^{* *}$ \\
Fat weight (kg) & $30.2 \pm 5.9$ & $37.12 \pm 3.92$ & $38.3 \pm 4.2$ & 0.0663 \\
lean weight (kg) & $35.8 \pm 2.6$ & $42.4 \pm 5.3$ & $58.8 \pm 12.1$ & $\mathbf{0 . 0 0 7 1}^{* *}$ \\
\hline
\end{tabular}

\section{Cell stimulation}

Monocytes were plated in 12-well plates (Costar, Corning Incorporated, Corning, NY, USA) at $1 \times 10^{6}$ cells/well concentration unless indicated otherwise. Cells were pre-treated with the potent, selective and reversible ceramide kinase (CERK) inhibitor NVP-231 (Tocris, $12 \mathrm{nM} / \mathrm{ml}$ ), then stimulated with TNF- $\alpha$ (10ng/ml) or Vehicle $\left(0.1 \%\right.$ BSA) for 2 hours at $37^{\circ} \mathrm{C}$. Cells were harvested for RNA isolation. To assess cytokines secretion (IL-b and MCP-1) in media, TNF- $\alpha$ stimulation was carried out for 12 hours. For MAPK's and NF-kB signaling pathway analysis, cultures were treated with the inhibitor as stated above then stimulated with TNF- $\alpha$ or BSA vehicle for 10-15 min.

\section{Lipidomics}


For lipid extraction, cells were washed with ice-cold PBS then directly lysed with $2 \mathrm{ml}$ cell extraction mixture (2:3 70\% isopropanol/ethyl acetate), followed by gentle scraping of the cells from the culture plate. The lysate was then transferred to $15 \mathrm{ml}$ Falcon tubes. The lipid samples were spiked with C17-SPH and C17-DHS (internal standards, 50pmol), and extracts were then analyzed by the Lipidomics Core Facility at Stony Brook University Medical Center, as described previously ${ }^{11}$. Data were normalized by total lipid phosphate $(\mathrm{Pi})$ present in the organic phase of the Bligh and Dyer extraction ${ }^{12}$ detected by phosphomolybdate assay ${ }^{13}$. Sphingolipid levels were expressed as pmol/nmol Pi.

\section{Real time quantitative RT-PCR}

Total RNA was extracted using RNeasy Mini Kit (Qiagen, Valencia. CA, USA) per the manufacturer's instructions. The cDNA was synthesized using $1 \mu \mathrm{g}$ of total RNA using high capacity cDNA reverse transcription kit (Applied Biosystems, Foster city, CA, USA). Real-time PCR was performed on 7500 Fast Real-Time PCR System (Applied Biosystems, Foster City, CA, USA) using TaqMan® Gene Expression Master Mix (Applied Biosystems, Foster city). Each reaction contained 25ng/ $\mu$ l cDNA that was amplified with Inventoried TaqMan Gene Expression Assay products (CERK: Assay ID: Hs00368483_m1; ITGAM (CD11b): Hs00355885_m1; ITGX (CD11c): Assay ID: Hs00174217_m1; GAPDH: Hs03929097_g1;). The threshold cycle $(\mathrm{Ct})$ values were normalized to the house-keeping gene GAPDH, and the amounts of target mRNA relative to control were calculated with $\Delta \Delta$ Ct-method ${ }^{14,15}$. Relative mRNA expression was expressed as fold expression over average of control gene expression. The expression level in control treatment was normalized to 1 . Values are presented as mean \pm SEM. Results were analyzed statistically; $\mathrm{P}<0.05$ was considered significant.

\section{Extracellular staining -flow cytometry}

Monocytic cells were seeded in 24 well plate at $0.5 \times 10^{5}$ cell $/ \mathrm{ml}$ in serum free media overnight. Cells were treated with CERK inhibitor NVP-231 (12nM for one hour or 0.01\% DMSO (vehicle) then subjected to 
stimulation with TNF- $\alpha(10 \mathrm{ng} / \mathrm{ml})$ or BSA (vehicle) for 6 hours. Monocytic cells $\left(1 \times 10^{6}\right.$ cells) were resuspended in FACS staining buffer (BD Biosciences) and blocked with human IgG (Sigma; 20 $\mu \mathrm{g}$ ) for 30 minutes on ice. Cells were washed and resuspended in $100 \mathrm{ul}$ of FACS buffer and incubated with CD11b (D12)-APC (cat\# 340936 ;BD Biosciences), CD11c (S_HCL-3)-PE (cat\# 347637 ;BD Biosciences) or CD11c PE-Cy7 (cat \# 117317, BD Biosciences ) on ice for 30 minutes. Cells were washed three times with FACS buffer and resuspended in 2\% paraformaldehyde. Cells were centrifuged and resuspended in FACS buffer for FACS analysis (FACSCanto II; BD Bioscience, San Jose, USA). FACS data analysis was performed using BD FACSDiva ${ }^{\mathrm{TM}}$ Software 8 (BD Biosciences, San Jose, USA).

\section{Intracellular Staining -flow Cytometry}

Flow cytometry analysis was used to investigate the expression of signaling pathway markers. Briefly, cells were seeded in 24 well plate at $0.5 \times 10^{5}$ cells $/ \mathrm{ml}$ in serum free media overnight. Cells were treated with the CERK inhibitor NVP-231 or DMSO (vehicle) then subjected to stimulation with TNF- $\alpha(10 \mathrm{ng} / \mathrm{ml})$ or BSA (vehicle) for $10 \mathrm{~min}$. After stimulation, cells were collected and washed. Cells were then incubated with fixation/permeabilization buffer (cat\# 00-5523-00, eBioscience, San Diego, CA, USA) for 20 min in $4^{\circ} \mathrm{C}$, followed by washing and staining with the following antibodies: mouse anti-human JNK-PE/ (pT183/pY185) (cat\# 562480), mouse anti-human p38 MAPK/ (pT180/pY182) (cat\# 612280), anti-human NF-kB P65-PE (cat \# 558423; BD Biosciences) or Alexa Fluor®647 mouse anti-IкB $\alpha$ (cat \# 560817; BD Biosciences) for $30 \mathrm{~min}$. The cells were then washed and resuspended in PBS supplemented with $2 \%$ FCS for FACS analysis (FACSCanto II; BD Bioscience, San Jose, USA). FACS data analysis was performed using BD FACSDivaTM Software 8 (BD Biosciences, San Jose, USA).

\section{IL-1b and MCP-1 determination}

Secreted IL-1b and MCP-1 protein in supernatants of monocytic cells stimulated with TNF- $\alpha$ was quantified using sandwich ELISA following the manufacturer's instructions (R\&D systems, Minneapolis, USA). 


\section{Small interfering RNA (siRNA) transfections}

Monocytes were washed and resuspended in 100 ul of nucleofector solution provided with the Amaxa Noclecfector Kit V and transfected separately with siRNA-CERK (30nM; OriGene Technologies, Inc. MD, USA), scramble (control) siRNA (30nM; OriGene Technologies, Inc. MD, USA, USA), and pmaxGFP (0.5 ug; Amaxa Noclecfector Kit V for THP-1, Lonza). All transfection experiments were performed with Amaxa Cell Line Nucleofector Kit $\mathrm{V}$ for monocytic cells(Lonza, Germany) by using Amaxa Electroporation System (Amaxa Inc, Germany) according to the manufacturer's protocol ${ }^{16}$. After 36 hours of transfection, cells were treated with TNF- $\alpha$ for 2 hours. Cells were transfected with $20 \mathrm{nM}$ of the siRNA using Viromer Blue (lipocalyx, Halle, Germany) as per manufacture's instruction. Cells were harvested for RNA isolation and staining study. CERK gene knock down level was assessed by Real Time-PCR using CERK gene specific primer (CERK: Assay ID: Hs00368483; ThermoFisher Sceintific).

\section{Measurement of $\mathrm{NF}-\kappa \mathrm{B}$ activity}

NF-kB reporter monocytes (THP-1 XBlue; InvivoGen, San Diego, CA) are stably transfected with a reporter construct, expressing a secreted embryonic alkaline phosphatase (SEAP) gene under the control of a promoter inducible by the transcription factors NF- $\kappa$ B. Upon stimulation, NF- $\kappa \mathrm{B}$ is activated and subsequently the secretion of SEAP is stimulated. Cells were stimulated with TNF- $\alpha(10 \mathrm{ng} / \mathrm{ml})$ for $6-12$ hours at $37^{\circ} \mathrm{C}$. Levels of SEAP were detected in the culture media after 3 hours incubation of supernatants with Quanti-Blue solution (InvivoGen, San Diego, CA, USA) at 650nm wavelength by ELISA reader.

\section{Western blotting}

THP-1 cells were harvested and incubated for $30 \mathrm{~min}$ with lysis buffer (Tris $62.5 \mathrm{mM}$ (pH 7.5), $1 \%$ Triton $\mathrm{X}-100,10 \%$ glycerol). The lysates were then centrifuged at $14000 \times \mathrm{g}$ for $10 \mathrm{~min}$ and the supernatants were collected. Protein concentration in lysates was measured by Quickstart Bradford Dye Reagent, 1x Protein Assay kit (Bio-Rad Laboratories, Inc, CA). Protein $(20 \mu \mathrm{g})$ samples were mixed with sample loading buffer, heated for $5 \mathrm{~min}$ at $95^{\circ} \mathrm{C}$ and resolved by $12 \%$ SDS-PAGE. Cellular proteins were transferred to Immuno- 
Blot PVDF membrane (Bio-Rad Laboratories, USA) by electroblotting. The membranes were then blocked with 5\% non-fat milk in PBS for $1 \mathrm{~h}$, followed by incubation with primary antibodies against p-SAPK/JNK,

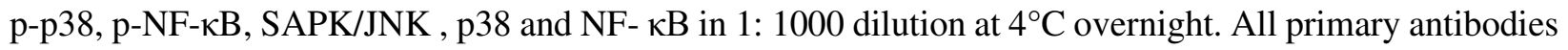
were purchased from Cell Signaling (Cell Signaling Technology, Inc). The blots were then washed four times with TBS and incubated for $2 \mathrm{~h}$ with HRP-conjugated secondary antibody (Promega, Madison, WI, USA). Immunoreactive bands were developed using an Amersham ECL plus Western Blotting Detection System (GE Health Care, Buckinghamshire, UK) and visualized by Molecular Imager ® ChemiDocTM MP Imaging Systems (Bio-Rad Laboratories, Hercules, CA, USA).

\section{Statistical Analysis}

Statistical analysis was performed using GraphPad Prism software (La Jolla, CA, USA). Data are shown as mean \pm standard error of the mean, unless otherwise indicated. Unpaired Student t-test and one-way ANOVA followed by tukey's test were used to compare means between groups. For all analyses, data from a minimum of three sample sets were used for statistical calculation. P value $<0.05$ was considered significant. Ns: no significance, $* \mathrm{P}<0.05, * * \mathrm{P}<0.01, * * * \mathrm{P}<0.001$ and $* * * * \mathrm{P}<0.0001)$

\section{RESULTS}

\section{CERK inhibition reduces TNF- $\alpha$ induced inflammatory responses in monocytes}

CERK and its by product C1P are involved in many pathophysiological inflammatory processes ${ }^{4}$. To investigate whether CERK is involved in TNF- $\alpha$-mediated immune responses, THP-1 monocytic cells were pre-treated with the specific CERK inhibitor NVP-231 before exposure to TNF- $\alpha$. Treatment with NVP231, followed by exposure to TNF- $\alpha$, caused a significant reduction in the expression of phenotypic monocyte inflammatory markers including CD11c, CD11b and HLA-DR at both the mRNA and protein levels (Fig. 1 A and B).

To further validate the physiological relevance of these data obtained from THP-1 cells, primary human monocytes were preincubated with NVP-231, followed by exposure to TNF- $\alpha$. Our results show that NVP- 
231 treatment inhibited the TNF- $\alpha$-induced CD11c and CD11b gene expression as well as CD14+CD11 ${ }^{+}$ and $\mathrm{CD} 14^{+} \mathrm{CD} 11 \mathrm{~b}^{+}$surface expression in primary human monocytes (Fig.2 A and B, respectively). Collectively these results suggest that CERK is involved in the TNF- $\alpha$-mediated upregulation of proinflammatory response in human monocytic cells.

\section{CERK inhibition reduces TNF- $\alpha-$-mediated IL-1ß and MCP-1 production}

IL-1 $\beta$ and MCP-1 produced by activated monocytes contribute to the pathogenesis of different inflammatory conditions ${ }^{17-19}$. Next, we asked whether IL-1 $\beta$ and MCP-1 expression induced by TNF- $\alpha$ in THP-1cells or in primary monocytes, was reduced by inhibition of CERK. Our data show that inhibition of CERK in THP-1 monocytes significantly reduced the production of IL-1 $1 \beta$ and MCP-1 following TNF- $\alpha$ stimulation (Fig. 3A and B). As expected, similar results were seen in primary monocytes (Fig. 3C and D). These results show evidence that TNF- $\alpha$ regulates the production of key inflammatory cytokines such as IL-1 $\beta$ and MCP-1 through the activation of CERK.

\section{CERK deficiency impairs the TNF- $\alpha$-mediated pro-inflammatory responses in human monocytes}

To further confirm the role of CERK in TNF- $\alpha$-induced inflammatory alterations in THP-1 monocytic cells and primary human monocytes, cells were transfected with siRNA against CERK reducing CERK mRNA levels by 50-70\% as compared with scramble (control) siRNA (Fig 4A and B). The expression of CD11c, CD11b and HLA, at both mRNA and protein levels, were significantly reduced in CERK-deficient THP-1 monocytes (Fig. 4C and D) as well as primary monocytes (Fig. 4E and F) after exposure to TNF- $\alpha$. Next, we wanted to see whether CERK deficiency in monocytic cells disrupted the TNF- $\alpha$-induced secretion of IL-1 $\beta$ and MCP-1. As expected, monocytic cells deficient in CERK failed to respond to TNF- $\alpha$ exposure regarding secretion of IL-1 $\beta$ and MCP-1when compared to cells treated with scrambled siRNA (Fig. 5AD). Altogether, our results suggest the significant involvement of CERK in inflammatory responses induced by TNF- $\alpha$ in monocytic cells. 


\section{TNF- $\alpha$ induces ceramide 1 phosphate in monocytic cells}

Since our data show that CERK is involved in TNF- $\alpha$-mediated monocytic cell activation and inflammatory responses, next we examined weather TNF- $\alpha$ induced the production of ceramide 1-phosphate (C1P). We measured ceramides and C1P levels following TNF- $\alpha$ stimulation. While TNF- $\alpha$ stimulation did not alter C16 or total ceramide levels (Fig. A-B), C16-C1P and total C1P levels were significantly increased. (Fig. 6A-D). These data suggest that TNF- $\alpha$ regulates the production of C1P.

\section{NVP-231 inhibits the TNF- $\alpha$ induced activation of MAPKs and NF-кB}

Since CERK/C1P activate the phosphorylation of JNK, p38 and NF- $\kappa B^{20}$, we questioned whether CERK was involved in TNF- $\alpha$-induced activation of JNK, p38 and NF- $\kappa B$ signaling pathways. To investigate the CERK function in the TNF- $\alpha$-mediated activation of MAPK and NF- $\kappa B$ signaling pathways, cells were pre-treated with CERK inhibitor (NVP-231) prior to TNF- $\alpha$ stimulation. Our results show that the inhibition of CERK significantly decreased TNF- $\alpha$-mediated phosphorylation of JNK, p38, and NF-kB (Fig. 7A- E, Supplementary Fig. 1A-C). NF- $\kappa$ B and AP-1 are downstream transcription factors of TNF- $\alpha$ signaling pathways. To further examine the role of CERK in TNF- $\alpha$-mediated activation of NF- $\kappa \mathrm{B} / \mathrm{AP}-1$, we used the NF- $\mathrm{KB} / \mathrm{AP}-1$ activity reporter human monocytic cells. Our data show that TNF- $\alpha$ induces higher NF$\kappa \mathrm{B} / \mathrm{AP}-1$ activity in the reporter cells and this activity was diminished in the cells that were treated with CERK inhibitor (Fig. 7F). Concordantly, TNF- $\alpha$-stimulated reporter cells also showed elevated surface expression of the activation marker CD11c which was also suppressed when the cells were treated with CERK inhibitor (Fig. 7G). Together, these data support the role of CERK in TNF- $\alpha$-mediated activation of NF-kB and AP-1 transcription factors.

\section{Increased gene expression of CERK and TNF- $\alpha$ in PBMCs of obese individuals}

Our in vitro data show the involvement of CERK in TNF- $\alpha$-mediated inflammatory responses in human monocytic cells and primary human macrophages. Next, we asked if these data were relevant to a clinical setting, depicting the CERK-TNF- $\alpha$ modulations in a metabolic disorder. Therefore, we determined the 
expression levels of CERK and TNF- $\alpha$ in PBMCs of lean, overweight, and obese individuals. To this end, we isolated total RNA from PBMCs of 26 individuals including lean, overweight, and obese, and determined the gene expression CERK and TNF- $\alpha$. Our data show that expression of both CERK and TNF$\alpha$ was elevated in obese as compared to lean individuals (Figs. 8A and B, respectively). Furthermore, CERK expression was positively correlated with that of TNF- $\alpha(r=0.59 ; \mathrm{p}=0.0013$ (Fig. 8C).

\section{DISCUSSION}

In the present study, we report that CERK plays a role in the regulation of TNF- $\alpha$-induced inflammatory responses in monocytic cells. Our data show that pharmacologic inhibition of CERK with NVP-231 ${ }^{21}$ or genetic knockdown with CERK-specific siRNA significantly suppressed the expression of inflammatory markers, such as CD11b, CD11c and HLA-DR on the human monocytes stimulated with TNF- $\alpha$. TNF- $\alpha$ mediated inflammatory immune cell polarization contributes to the pathogenesis of many inflammatory diseases ${ }^{22-24}$. Elevated levels of TNF- $\alpha$ are persistently expressed in obesity and metabolic syndrome. Of note, obese mice and humans show increased numbers of monocytes/macrophages with elevated expression of CD11c marker as well as MCP-1 production under the influence of diet-induced obesity. On the other hand, CD11c deficiency in mice led to decreased inflammation in the animals, marked by reduced expression of inflammatory markers including HLA-DR, CCL5, and CCL4 ${ }^{25}$. CD11b expression was reported to be elevated in obese individuals which associated with the development of metabolic syndrome 26. CD11c expression was found to be higher in adipose-resident HLA-DR ${ }^{+}$macrophages from obese women ${ }^{27}$. Since TNF- $\alpha$ is invariably elevated in obesity and metabolic syndrome, expression of inflammatory phenotypic markers in monocytes/macrophages could have been induced by TNF- $\alpha$.

Given that CERK has been suggested to have roles in inflammation though not clearly defined, we set out to determine the possible involvement of CERK in TNF- $\alpha$-induced inflammation. The results showed that TNF- $\alpha$-induced C1P levels in monocytic cells, demonstrating activation of CERK. Inflammatory role of $\mathrm{C} 1 \mathrm{P}$ was first reported in lung adenocarcinoma cells; C1P stimulated the release of arachidonic acid in lung cancer cells and led to the production of eicosanoids which are implicated in inflammation ${ }^{28}$. C1P-mediated 
inflammation is directly regulated by activation of cytosolic phospholipase-A2a (cPLA2a), an enzyme that releases AA from membrane phospholipids ${ }^{29}$. CERK knockout mice expressed decreased levels of proinflammatory cytokines as well as less macrophage infiltration in adipose tissue when fed high fat diets compared to their wild type counterparts ${ }^{30}$. Our findings specifically show that CERK inhibition or its deficiency in monocytic cells significantly blocks the production of critical inflammatory mediators including IL-1 $\beta$ and MCP-1. We reported previously that knockdown of CERK led to a significant decrease in CCL5 mRNA and protein expression following TNF- $\alpha$ stimulation ${ }^{31}$. IL-1 $\beta$ and MCP-1 are the major proinflammatory mediators produced mostly by the activated monocytes/macrophage. Accumulating evidence confirms that IL-1 $\beta$ and MCP-1 are critically involved in obesity-associated inflammation in the rodent models ${ }^{32,33}$. IL-1 $\beta$ and MCP-1 are expressed in the human adipose tissues, but primarily by the nonfat cells ${ }^{32}$. In obese mice and humans, adipose tissue IL-1 $\beta$ and MCP-1 mRNA expression as well as their circulating levels correlated positively with insulin resistance. On the other hand, IL-1 $\beta$ and MCP-1 inhibition reduced the insulin resistance and adipose tissue inflammation in obese mice ${ }^{34}$. Furthermore, IL-1 $\beta$ and MCP-1 produced by TNF $\alpha$-stimulated mouse adipocytes/monocytes were shown to induce insulin resistance in the liver and adipose tissues ${ }^{35,36}$.

MAPKs and NF- $\kappa B$ signaling pathways get potently activated in the cells treated with TNF- $\alpha$. These pathways are commonly involved in the regulation of various inflammatory mediators that associate with the pathogenesis of different inflammatory diseases ${ }^{37}$. Importantly, MAPK signaling molecules cooperate with each other as well as with other inflammatory pathways including NF- $\kappa \mathrm{B}$ to elicit immune responses that are implicated in metabolic inflammation ${ }^{38,39}$. We and others have previously reported the role of ERK, JNK and NF- $\kappa B$ signaling in the regulation of TNF- $\alpha$-mediated expression of multiple inflammatory mediators such as IL-8, MCP-1 and MIP-1 $\alpha$ in monocytes and fibroblasts. These studies collectively point to the significance of MAPK and NF- $\mathrm{KB}$ pathways in inflammation through the regulation of various inflammatory mediators. Similarly, TNF- $\alpha$-induced expression of CD11c and IL-1 $\beta$ in the lungs of mice involved the p38 MAPK signaling ${ }^{40}$. It was previously shown that p38 signaling was implicated in nSMase 2 phosphorylation and activation. Our data are corroborated by a previous study ${ }^{31}$ showing that 
disrupting CERK activity by either NVP-231 or siRNA decreases the TNF- $\alpha$-induced phosphorylation of p38 MAPK, JNK, and NF- $\kappa$ B. TNF- $\alpha$ binding to its cognate receptor on cell surface receptor phosphorylates the downstream c-Jun and NF- $\kappa \beta$, resulting in the activation of several inflammatory genes. In line with these observations, we show that CERK inhibition significantly suppressed the TNF- $\alpha$-induced NF-KB/AP-1 activity in the reporter cells, pointing to a major role of CERK in TNF- $\alpha$-induced inflammatory responses in monocytes cells. In the line with our data, a study reported that C1P regulated cell survival via activating the $\mathrm{PI} 3-\mathrm{K} / \mathrm{PKB} / \mathrm{NF}-\kappa \mathrm{B}$ signaling pathway in mammalian cells ${ }^{41}$. In addition, ERK phosphorylation was demonstrated in human osteoblastic cells that were stimulated with short-chain $\mathrm{C} 1 \mathrm{P}^{42}$.

Overall, our data point to an interesting role of CERK and C1P in the regulation of TNF- $\alpha$-induced inflammatory responses in monocytic cells through the mechanism involving MAPK and NF- $\mathrm{B}$ signaling (Fig.9). Given that the data show reduced monocyte inflammatory responses following CERK inhibition or knockdown, further studies will be required to validate whether CERK targeting can be useful to alleviate chronic inflammation and insulin resistance in metabolic disorders.

In conclusion, our study supports a novel role of CERK in the regulation of TNF- $\alpha$-induced inflammatory responses in monocytic cells and primary human macrophages, involving the MAPK and NF- $\kappa \mathrm{B}$ signaling pathways. We further point to the possible link between TNF- $\alpha$ and CERK in obesity that could promote metabolic inflammation.

\section{Acknowledgements}

This work was supported by Kuwait Foundation for the Advancement of Sciences (KFAS) grant RA AM 2016- 007, RA 2010-003 to RA and NIH grant P01 CA097132 to YAH.

\section{Conflict of interest}

The authors declare no conflict of interests and no permission is required for publication. 


\section{Author contributions}

FA, ZA, AS, RT, SK, MM and SS performed experiments, analyzed data and participated in writing manuscript; LO, FAM, YAH participated in designing, planning experiments and in critical review and editing manuscript; RA planned, designed experimental work, interpreted data and wrote the manuscript.

\section{REFERENCES}

1 Schwalm, S. et al. Ceramide Kinase Is Upregulated in Metastatic Breast Cancer Cells and Contributes to Migration and Invasion by Activation of PI 3-Kinase and Akt. Int J Mol Sci 21, doi:10.3390/ijms21041396 (2020).

2 Ordoñez, M., Presa, N., Trueba, M. \& Gomez-Muñoz, A. Implication of Ceramide Kinase in Adipogenesis. Mediators Inflamm 2017, 9374563, doi:10.1155/2017/9374563 (2017).

3 Presa, N. et al. Regulation of cell migration and inflammation by ceramide 1-phosphate. Biochim Biophys Acta 1861, 402-409, doi:10.1016/j.bbalip.2016.02.007 (2016).

4 Arana, L. et al. Ceramide 1-phosphate induces macrophage chemoattractant protein-1 release: involvement in ceramide 1-phosphate-stimulated cell migration. Am J Physiol Endocrinol Metab 304, E1213-1226, doi:10.1152/ajpendo.00480.2012 (2013).

5 Mitsutake, S. et al. Ceramide kinase deficiency improves diet-induced obesity and insulin resistance. FEBS Lett 586, 1300-1305, doi:10.1016/j.febslet.2012.03.032 (2012).

6 Wouters, K. et al. Circulating classical monocytes are associated with CD11c. Sci Rep 7, 42665, doi:10.1038/srep42665 (2017).

7 Deng, T. et al. Class II major histocompatibility complex plays an essential role in obesity-induced adipose inflammation. Cell Metab 17, 411-422, doi:10.1016/j.cmet.2013.02.009 (2013).

8 Braune, J. et al. IL-6 Regulates M2 Polarization and Local Proliferation of Adipose Tissue Macrophages in Obesity. J Immunol 198, 2927-2934, doi:10.4049/jimmunol.1600476 (2017).

9 Ahmad, R. et al. The Synergy between Palmitate and TNF- $\alpha$ for CCL2 Production Is Dependent on the TRIF/IRF3 Pathway: Implications for Metabolic Inflammation. J Immunol 200, 3599-3611, doi:10.4049/jimmunol.1701552 (2018).

10 Ahmad, R., El Bassam, S., Cordeiro, P. \& Menezes, J. Requirement of TLR2-mediated signaling for the induction of IL-15 gene expression in human monocytic cells by HSV-1. Blood 112, 2360-2368, doi:10.1182/blood-2008-02-137711 (2008).

11 Bielawski, J. et al. Comprehensive quantitative analysis of bioactive sphingolipids by highperformance liquid chromatography-tandem mass spectrometry. Methods in molecular biology 579, 443-467 (2009).

12 Bligh, E. G. \& Dyer, W. J. A RAPID METHOD OF TOTAL LIPID EXTRACTION AND PURIFICATION. Canadian Journal of Biochemistry and Physiology 37, 911-917, doi:10.1139/o59-099 (1959).

13 Van Veldhoven, P. P. \& Bell, R. M. Effect of harvesting methods, growth conditions and growth phase on diacylglycerol levels in cultured human adherent cells. Biochimica et Biophysica Acta (BBA) - Lipids and Lipid Metabolism 959, 185-196, doi:http://dx.doi.org/10.1016/00052760(88)90030-6 (1988). 
14 Wray, G. M., Foster, S. J., Hinds, C. J. \& Thiemermann, C. A cell wall component from pathogenic and non-pathogenic gram-positive bacteria (peptidoglycan) synergises with endotoxin to cause the release of tumour necrosis factor-alpha, nitric oxide production, shock, and multiple organ injury/dysfunction in the rat. Shock 15, 135-142 (2001).

15 Al-Rashed, F., Kochumon, S., Usmani, S., Sindhu, S. \& Ahmad, R. Pam3CSK4 Induces MMP-9 Expression in Human Monocytic THP-1 Cells. Cell Physiol Biochem 41, 1993-2003, doi:10.1159/000475298 (2017).

16 Sindhu, S., Al-Roub, A., Koshy, M., Thomas, R. \& Ahmad, R. Palmitate-Induced MMP-9 Expression in the Human Monocytic Cells is Mediated through the TLR4-MyD88 Dependent Mechanism. Cell Physiol Biochem 39, 889-900, doi:10.1159/000447798 (2016).

17 Marriott, H. M. et al. Interleukin-1 $\beta$ regulates CXCL8 release and influences disease outcome in response to Streptococcus pneumoniae, defining intercellular cooperation between pulmonary epithelial cells and macrophages. Infect Immun 80, 1140-1149, doi:10.1128/IAI.05697-11 (2012).

Chen, M., Forrester, J. V. \& Xu, H. Dysregulation in retinal para-inflammation and age-related retinal degeneration in CCL2 or CCR2 deficient mice. PLoS One 6, e22818, doi:10.1371/journal.pone.0022818 (2011).

19 Jamali, Z. et al. Expression of CC chemokines CCL2, CCL5, and CCL11 is associated with duration of disease and complications in type-1 diabetes: a study on Iranian diabetic patients. Clin Lab 59, 993-1001 (2013).

20 Gangoiti, P. et al. Ceramide 1-phosphate stimulates macrophage proliferation through activation of the PI3-kinase/PKB, JNK and ERK1/2 pathways. Cell Signal 20, 726-736, doi:10.1016/j.cellsig.2007.12.008 (2008).

21 Graf, C. et al. Targeting ceramide metabolism with a potent and specific ceramide kinase inhibitor. Mol Pharmacol 74, 925-932, doi:10.1124/mol.108.048652 (2008).

22 Aggarwal, B. B. Signalling pathways of the TNF superfamily: a double-edged sword. Nat Rev Immunol 3, 745-756, doi:10.1038/nri1184 (2003).

23 De Taeye, B. M. et al. Macrophage TNF-alpha contributes to insulin resistance and hepatic steatosis in diet-induced obesity. Am J Physiol Endocrinol Metab 293, E713-725, doi:10.1152/ajpendo.00194.2007 (2007).

24 Ahmad, R. et al. TNF- $\alpha$ Drives the CCL4 Expression in Human Monocytic Cells: Involvement of the SAPK/JNK and NF-KB Signaling Pathways. Cell Physiol Biochem 52, 908-921, doi:10.33594/000000063 (2019).

$25 \mathrm{Wu}, \mathrm{H}$. et al. CD11c expression in adipose tissue and blood and its role in diet-induced obesity. Arterioscler Thromb Vasc Biol 30, 186-192, doi:10.1161/ATVBAHA.109.198044 (2010).

26 Boschmann, M. et al. Adipose tissue metabolism and CD11b expression on monocytes in obese hypertensives. Hypertension 46, 130-136, doi:10.1161/01.HYP.0000171477.63859.b2 (2005).

27 Bravo-Flores, E. et al. Macrophage Populations in Visceral Adipose Tissue from Pregnant Women: Potential Role of Obesity in Maternal Inflammation. Int J Mol Sci 19, doi:10.3390/ijms19041074 (2018).

28 Gomez-Muñoz, A. The Role of Ceramide 1-Phosphate in Tumor Cell Survival and Dissemination. Adv Cancer Res 140, 217-234, doi:10.1016/bs.acr.2018.04.012 (2018).

29 Lamour, N. F. \& Chalfant, C. E. Ceramide kinase and the ceramide-1-phosphate/cPLA2alpha interaction as a therapeutic target. Curr Drug Targets 9, 674-682, doi:10.2174/138945008785132349 (2008).

30 Hait, N. C. \& Maiti, A. The Role of Sphingosine-1-Phosphate and Ceramide-1-Phosphate in Inflammation and Cancer. Mediators Inflamm 2017, 4806541, doi:10.1155/2017/4806541 (2017).

31 Newcomb, B. et al. Identification of an acid sphingomyelinase ceramide kinase pathway in the regulation of the chemokine CCL5. J Lipid Res 59, 1219-1229, doi:10.1194/jlr.M084202 (2018). 
32 Bing, C. Is interleukin-1 $\beta$ a culprit in macrophage-adipocyte crosstalk in obesity? Adipocyte 4, 149152, doi:10.4161/21623945.2014.979661 (2015).

33 Kim, C. S. et al. Circulating levels of MCP-1 and IL-8 are elevated in human obese subjects and associated with obesity-related parameters. Int J Obes (Lond) 30, 1347-1355, doi:10.1038/sj.ijo.0803259 (2006).

34 Shi, J., Fan, J., Su, Q. \& Yang, Z. Cytokines and Abnormal Glucose and Lipid Metabolism. Front Endocrinol (Lausanne) 10, 703, doi:10.3389/fendo.2019.00703 (2019).

35 Nov, O. et al. Interleukin-1 $\beta$ regulates fat-liver crosstalk in obesity by auto-paracrine modulation of adipose tissue inflammation and expandability. PLoS One 8, e53626, doi:10.1371/journal.pone.0053626 (2013).

36 Mandrekar, P., Ambade, A., Lim, A., Szabo, G. \& Catalano, D. An essential role for monocyte chemoattractant protein-1 in alcoholic liver injury: regulation of proinflammatory cytokines and hepatic steatosis in mice. Hepatology 54, 2185-2197, doi:10.1002/hep.24599 (2011).

37 Shi, J. H. \& Sun, S. C. Tumor Necrosis Factor Receptor-Associated Factor Regulation of Nuclear Factor KB and Mitogen-Activated Protein Kinase Pathways. Front Immunol 9, 1849, doi:10.3389/fimmu.2018.01849 (2018).

38 Tibbles, L. A. \& Woodgett, J. R. The stress-activated protein kinase pathways. Cell Mol Life Sci 55, 1230-1254, doi:10.1007/s000180050369 (1999).

39 Kyriakis, J. M. \& Avruch, J. Mammalian MAPK signal transduction pathways activated by stress and inflammation: a 10-year update. Physiol Rev 92, 689-737, doi:10.1152/physrev.00028.2011 (2012).

40 Gupta, J. \& Nebreda, A. R. Roles of p38a mitogen-activated protein kinase in mouse models of inflammatory diseases and cancer. FEBS J 282, 1841-1857, doi:10.1111/febs.13250 (2015).

41 Gómez-Muñoz, A., Gangoiti, P., Granado, M. H., Arana, L. \& Ouro, A. Ceramide-1-phosphate in cell survival and inflammatory signaling. Adv Exp Med Biol 688, 118-130, doi:10.1007/978-1-44196741-1_8 (2010).

42 Carpio, L. C., Stephan, E., Kamer, A. \& Dziak, R. Sphingolipids stimulate cell growth via MAP kinase activation in osteoblastic cells. Prostaglandins Leukot Essent Fatty Acids 61, 267-273, doi:10.1054/plef.1999.0100 (1999).

\section{FIGURE LEGENDS}

Figure 1. CERK inhibition blocks TNF- $\alpha$ mediated pro-inflammatory changes in THP1.

Cells were pretreated with CERK inhibitors (NVP-231: 12nM) or vehicle for 1 hour and then incubated with TNF- $\alpha$ for 2 hours. Cells were harvested and mRNA expression for CD11c, CD11b and HLA-Dr was determined by real time RT-PCR (A). After 6 hours treatment with TNF- $\alpha$, cells were stained with antibodies against CD11c, CD11b ad HLA-Dr along with matched isotype controls. Surface expression were assessed by flow cytometry (B) data are presented as a bar graph of mean staining index, and 
representative histogram. All data are expressed as mean $\pm \operatorname{SEM}(n \geq 3) \cdot{ }^{*} \mathrm{p} \leq 0.05, * * p \leq 0.01, * * * p \leq 0.001$, $* * * * \mathrm{p} \leq 0.0001$ versus vehicle.

Figure 2. CERK inhibition blocks TNF- $\alpha$ mediated pro-inflammatory changes in primary human monocytes.

Human primary monocytes were pretreated with CERK inhibitor (NVP-231: 12nM) or vehicle for 1 hour and then incubated with TNF- $\alpha$ for 2 hours. Cells were harvested and mRNA expression for CD11c and CD11b was determined by real time RT-PCR (A). After 6 hours treatment with TNF- $\alpha$, cells were stained with antibodies against CD11c, CD11b and CD14 along with matched isotype controls. Surface expression of $\mathrm{CD} 14^{+} \mathrm{CD} 11 \mathrm{c}^{+}$and $\mathrm{CD} 14^{+} \mathrm{CD} 11 \mathrm{~b}^{+}$were assessed by flow cytometry $(\mathbf{B})$ data are presented as a bar graph of mean staining index, and representative histogram. All data are expressed as mean \pm SEM ( $\mathrm{n} \geq 3)$. $* \mathrm{p} \leq 0.05, * * \mathrm{p} \leq 0.01, * * * \mathrm{p} \leq 0.001, * * * * \mathrm{p} \leq 0.0001$ versus vehicle.

Figure 3. IL-1b and MCP-1 secreted by TNF- $\alpha$ activated monocytes are suppressed by CERK inhibition.

Monocytic cells (primary monocytes, macrophages, THP1 cells) were pretreated with CERK inhibitor (NVP-231: 12nM) or vehicle for 1 hour and then incubated cells with absence or presence of TNF- $\alpha$ for 12 hours. Secreted IL-1b and MCP-1 protein in culture media was determined by ELISA. IL-1b and MCP1 secreted by THP1 cells (A and B), and primary monocytes (C and D). All data are expressed as mean \pm $\operatorname{SEM}(\mathrm{n} \geq 3) .{ }^{*} \mathrm{p} \leq 0.05, * * \mathrm{p} \leq 0.01, * * * \mathrm{p} \leq 0.001, * * * * \mathrm{p} \leq 0.0001$ versus vehicle.

Figure 4. TNF- $\alpha$ mediated pro-inflammatory monocytic responses require CERK.

THP1 monocytes and Primary monocytes were transfected with scramble-siRNA (negative control; NC) or CERK siRNA and incubated for 36 hours. Real-time PCR was performed to measure (A) CERK expression in THP1 monocytic cells and (B) primary monocytes. CERK deficient THP1 cells were treated with TNF- $\alpha$ and vehicle. Cells were stained with antibodies against CD11c, CD11b and HLA-Dr along 
with matched isotypes and were subjected to flow cytometry analysis. Flow cytometry data are presented as a bar graph of mean staining index of the inflammatory markers (C). CD11c, CD11b and HLA-Dr were determined by real time RT-PCR (D). primary monocyte surface expression of $\mathrm{CD} 14^{+} \mathrm{CD} 11 \mathrm{c}^{+}$and $\mathrm{CD} 14^{+} \mathrm{CD} 11 \mathrm{~b}^{+}$was determined by flow cytometry along with matched isotypes control (E) CD11c and CD11b mRNA were determined by real time RT-PCR $(\mathbf{F})$. All data are expressed as mean \pm SEM $(n \geq 3)$. ${ }^{*} \mathrm{p} \leq 0.05, * * \mathrm{p} \leq 0.01, * * * \mathrm{p} \leq 0.001, * * * * \mathrm{p} \leq 0.0001$ versus vehicle.

Figure 5. CERK deficiency attenuates IL-1b and MCP-1 secretion induced by TNF- $\alpha$ activated monocytes.

THP1 monocytes and Primary monocytes were transfected with scramble-siRNA (negative control; NC) or CERK siRNA and incubated for 36 hours. CERK deficient THP1 and primary monocytes were treated with TNF- $\alpha$ for 12 hours. Secreted IL-1b and MCP-1 protein in culture media was determined by ELISA. IL-1b and MCP1 secreted by THP1 cells (A and B), and primary monocytes (C and D). All data are expressed as mean $\pm \operatorname{SEM}(\mathrm{n} \geq 3) .{ }^{*} \mathrm{p} \leq 0.05,{ }^{* *} \mathrm{p} \leq 0.01, * * * \mathrm{p} \leq 0.001, * * * * \mathrm{p} \leq 0.0001$ versus vehicle.

\section{Figure 6. TNF- $\alpha$ induces ceramides in monocytic cells}

THP-1 monocytes were treated with vehicle or TNF- $\alpha$ for 12 hours. Cellular lipid levels were analyzed A) C16 ceramide, B) total ceramides, C) C16 C1P, D) total C1P by ESI/MS/MS in the Stony Brook University Lipidomics Shared Resource Core and normalized to total lipid phosphate (Pi). Data represent mean \pm SEM, $\mathrm{n}=4,{ }^{*} \mathrm{p}<0.05$ as compared to Vehicle treatment.

Figure 7. Inhibition of CERK affects TNF- $\alpha$ activated MAPK and NF-кB signaling pathways in THP1 cells.

THP1 Monocytic cells were pretreated with CERK inhibitor (NVP-231: 12nM) and then incubated with TNF- $\alpha$. Cell lysates were prepared as described in material and methods. Samples were run on denaturing gels. Immuno-reactive bands were developed using an Amersham ECL Plus Westren Blotting Detection 
System (GE Healthcare, Chicago, IL, USA) and visualized by Molecular Imager ${ }^{\circledR}$ ChemiDoc ${ }^{\mathrm{TM}}$ MP Imaging Systems (Bio-Rad Laboratories, Hercules, CA, USA). (A) Phosphorylated proteins of SPAK/JNK, (B) p38 and (C) NF-kB are shown in the upper panels with the lower panel representing respective total proteins. The phosphorylation intensity was quantified by using Image Lab software (version 6.0.1, BioRad, Hercules, CA, USA) and are presented in bar graphs in arbitrary unit of corrected protein expression. Signaling proteins were also determined by Flow cytometry. Cell were immediately fixed and permeabilize for $20 \mathrm{~min}$ at $4^{\circ} \mathrm{C}$ then stained to visualize for JNK, p38 and NF- $\kappa \mathrm{B}$ phosphorylation. Flow cytometry data are presented as a bar graph of mean staining index (SI) as well as and representative histogram (D and E). Bar graphs depict mean values \pm SEM of staining intensity (SI). $\mathrm{P}<0.05$ was considered as statistically significant $(* \mathrm{P} \leq 0.05 ; * * \mathrm{P} \leq 0.01, * * * \mathrm{P} \leq 0.001, * * * * \mathrm{P} \leq 0.0001)$. The data in all Figures are representative of three independent experiments. NF-אB/AP-1 reporter monocytic cells were pretreated with CERK inhibitor (NVP-231: $12 \mathrm{nM}$ ) or vehicle for 1 hour and then incubated with TNF- $\alpha$ for 12 hours. Cell culture media were assayed for SEAP reporter activity (degree of NF-אB activation) $(\mathbf{F})$. Reporter cells were also tested for expression of CD11c $(\mathbf{G})$.

\section{Figure 8. Association of elevated TNF- $\alpha$ with CERK levels in obese human PBMCs.}

PBMCs were isolated from human blood samples obtained from lean $(n=13)$, overweight $(n=14)$ and obese $(\mathrm{n}=13)$ individuals. mRNA of CERK and TNF- $\alpha$ were detected by real time RT-PCR and represented as fold change over controls (A and B). Pearson's correlation coefficient (r) conducted between CERK and TNF- $\alpha(\mathbf{C})$.

Figure 9. Schematic illustration summarizing the involvement of CERK in TNF- $\alpha$ mediated inflammatory responses in human monocytic cells. Figure is created by BioRender.com. 


\section{Figure 1}

A

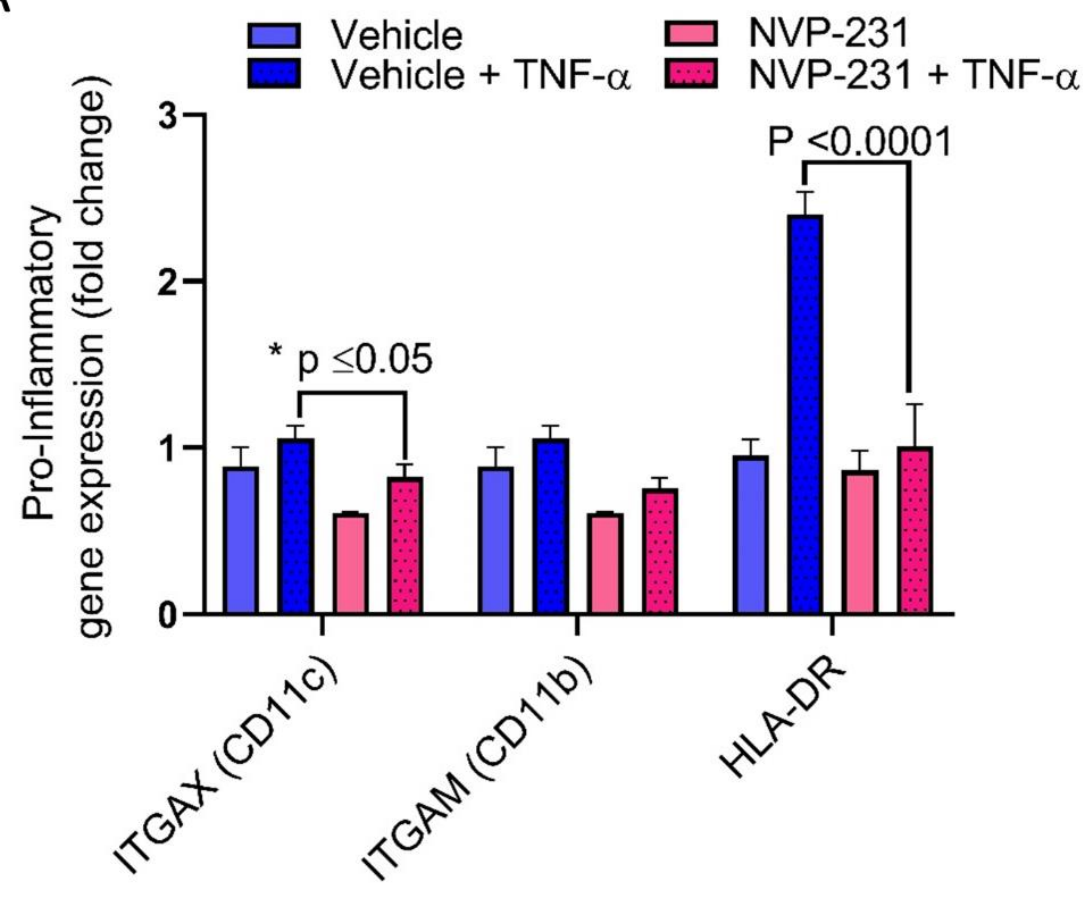

B
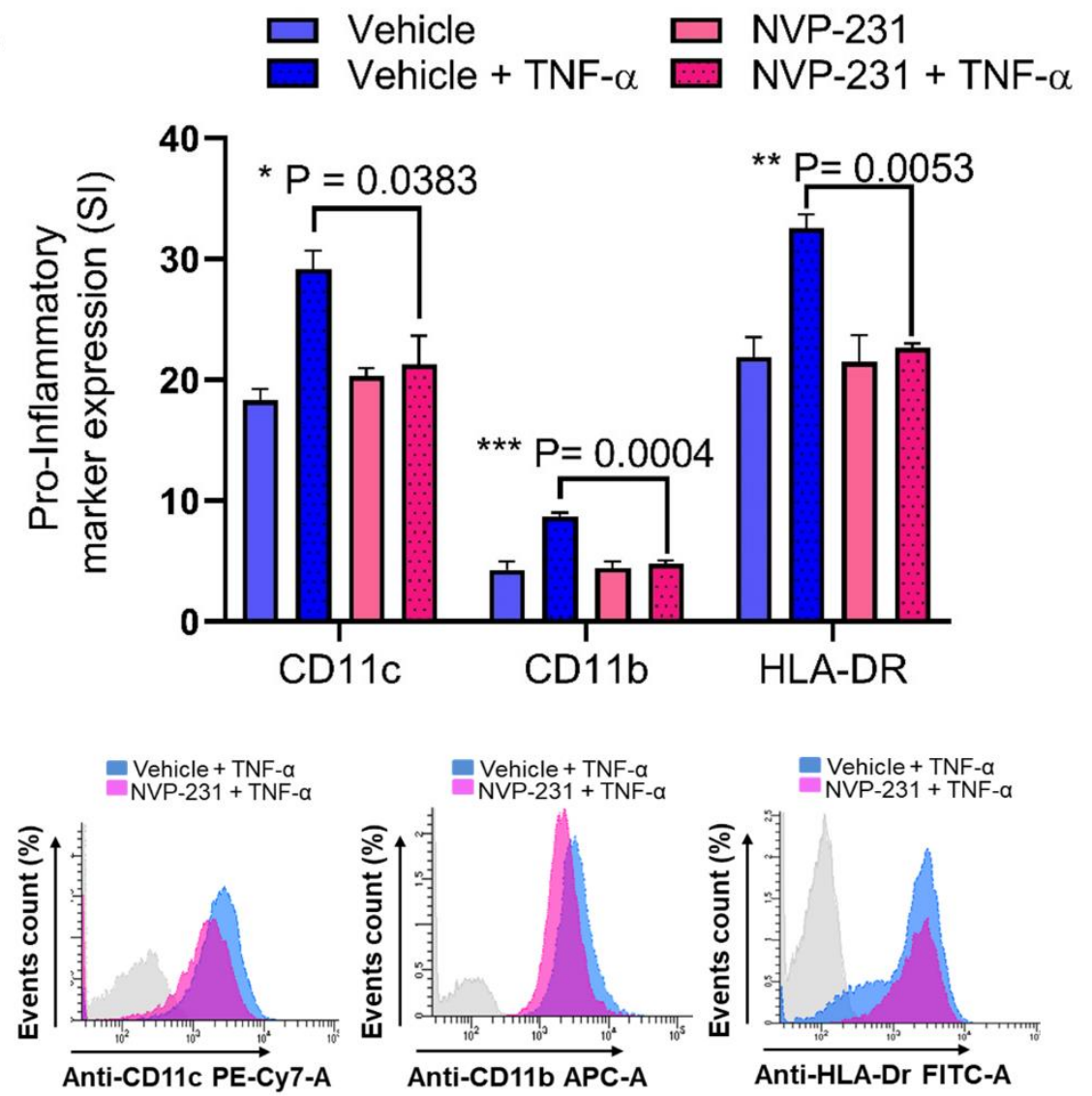


\section{Figure 2}
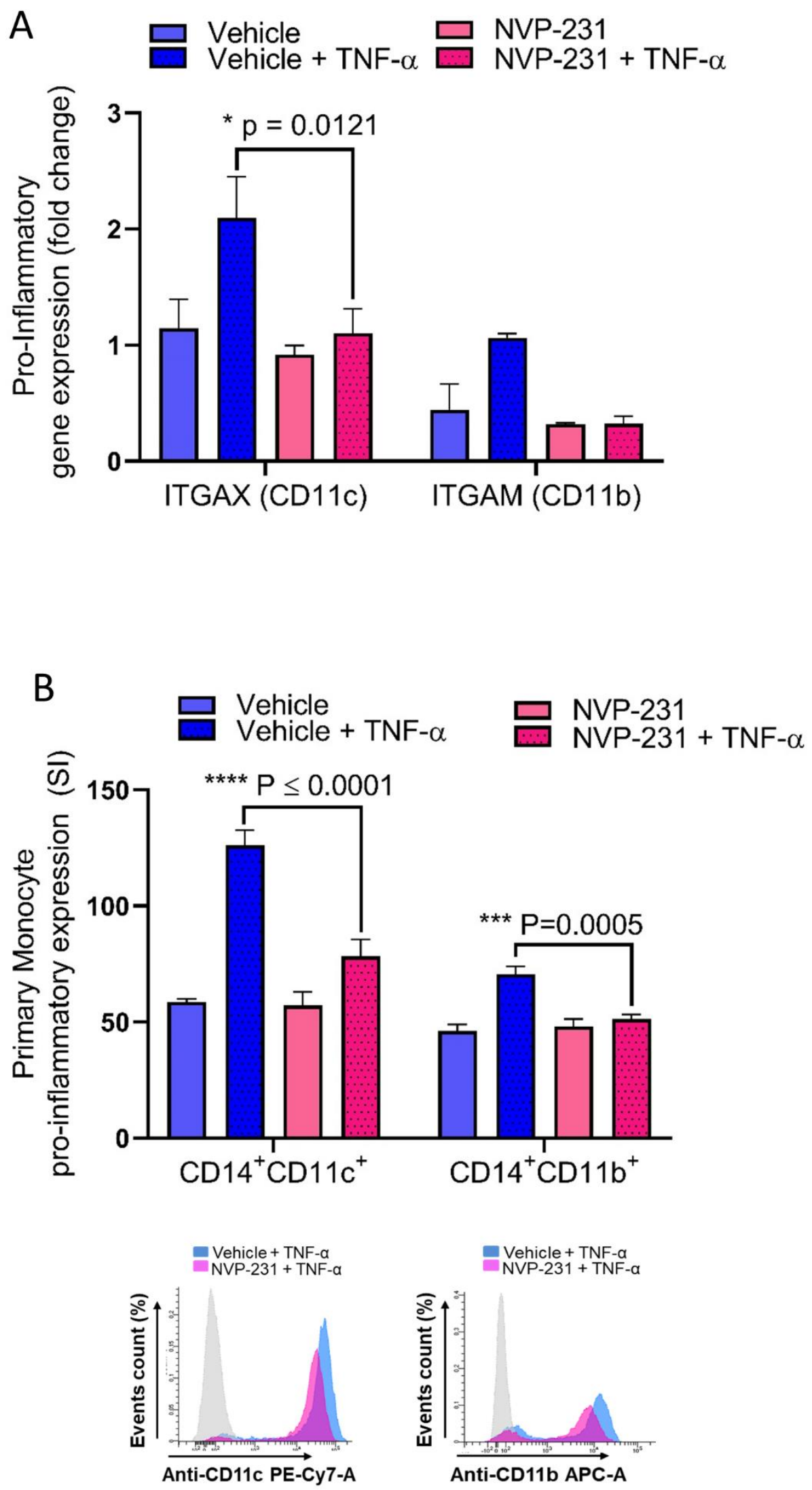
Figure 3

A

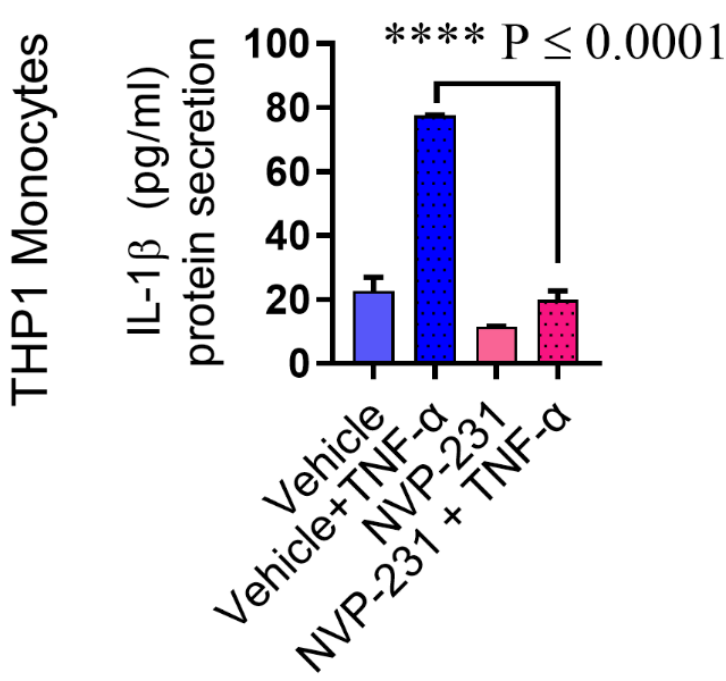

C

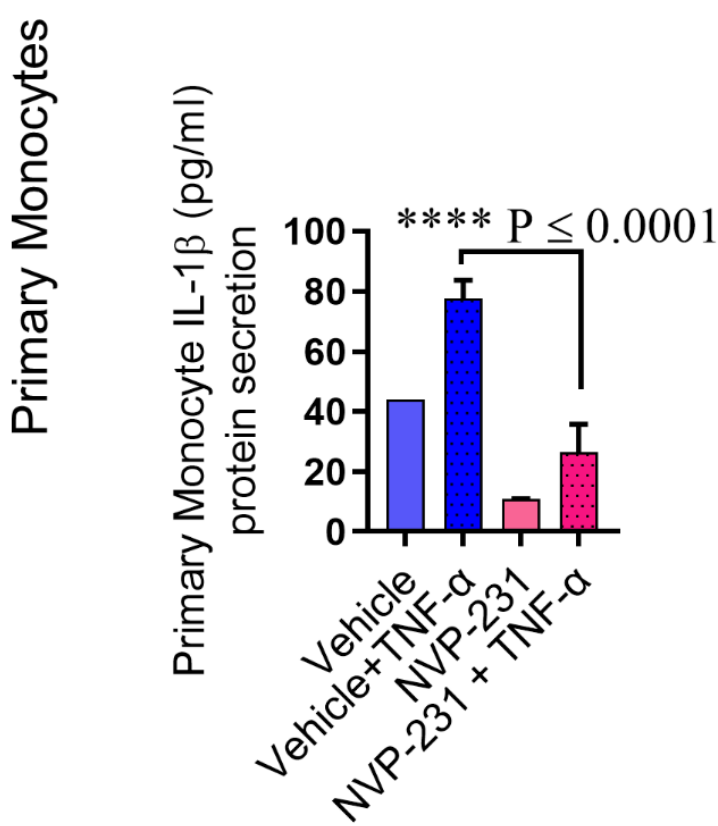

B

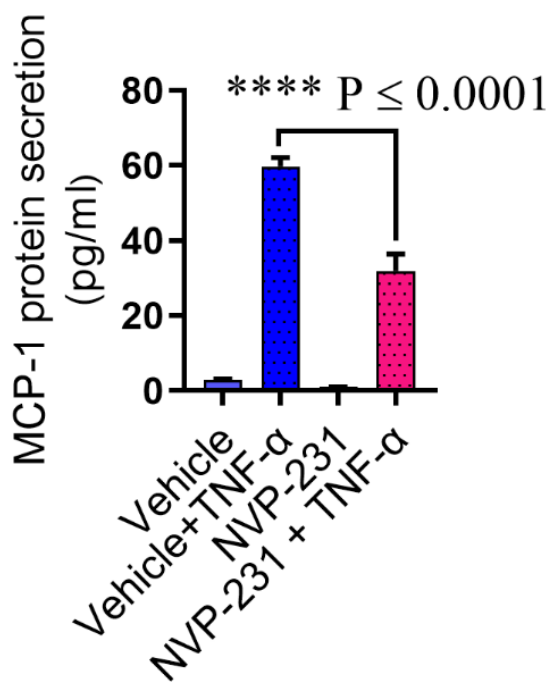

D

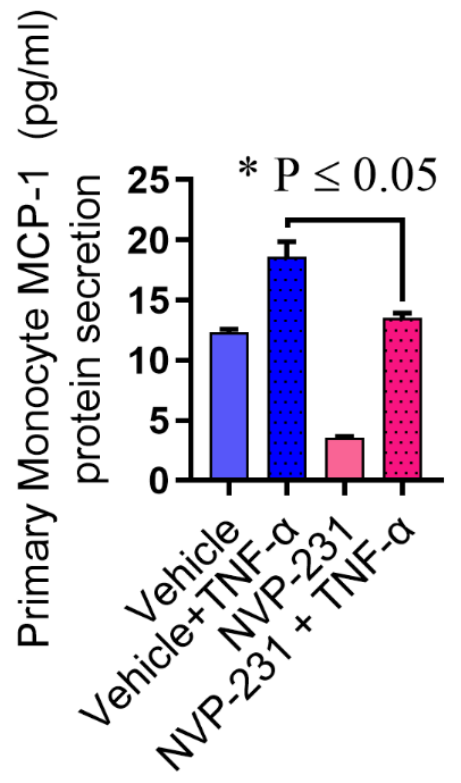


Figure 4
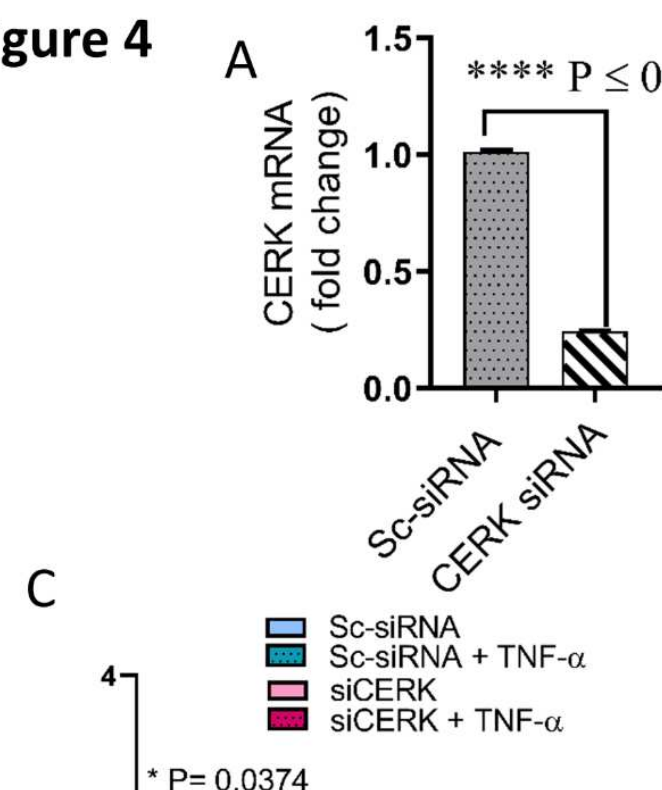

D
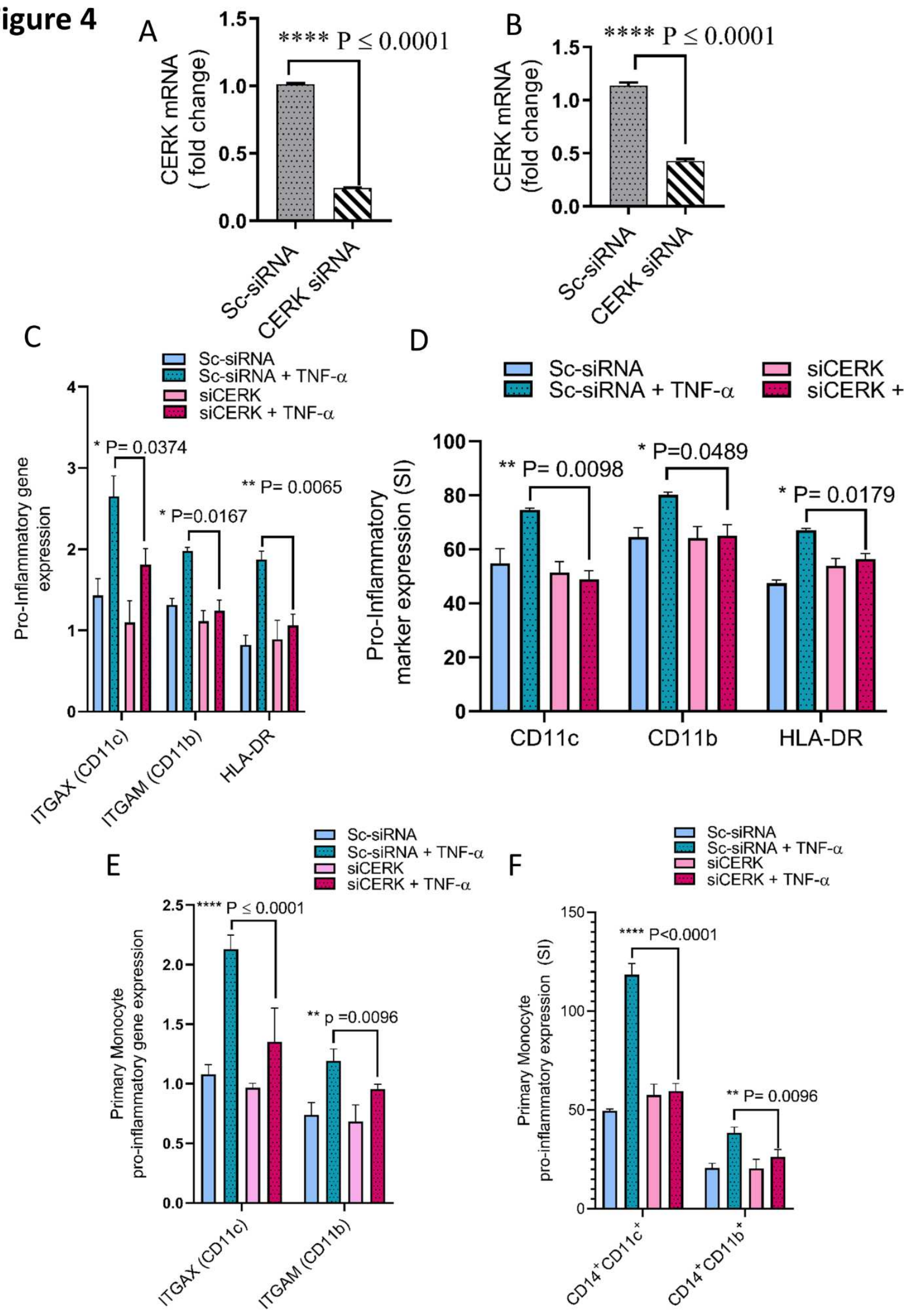
Figure 5

A

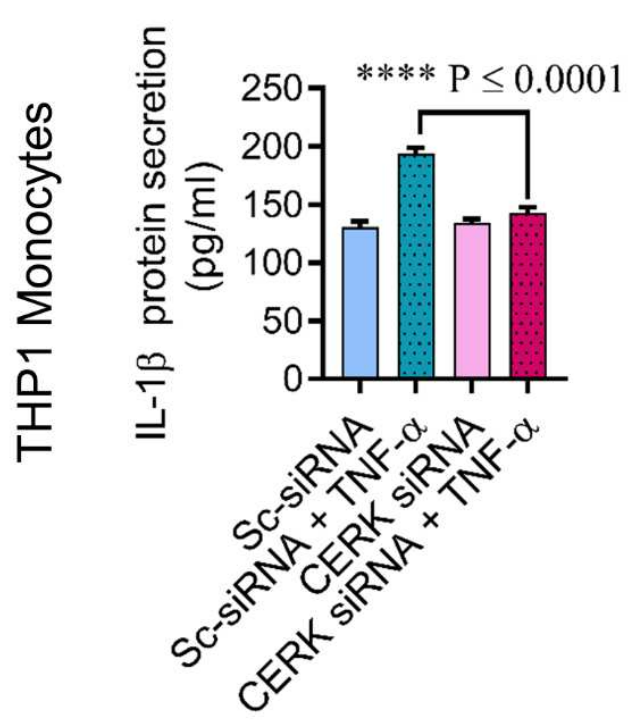

C

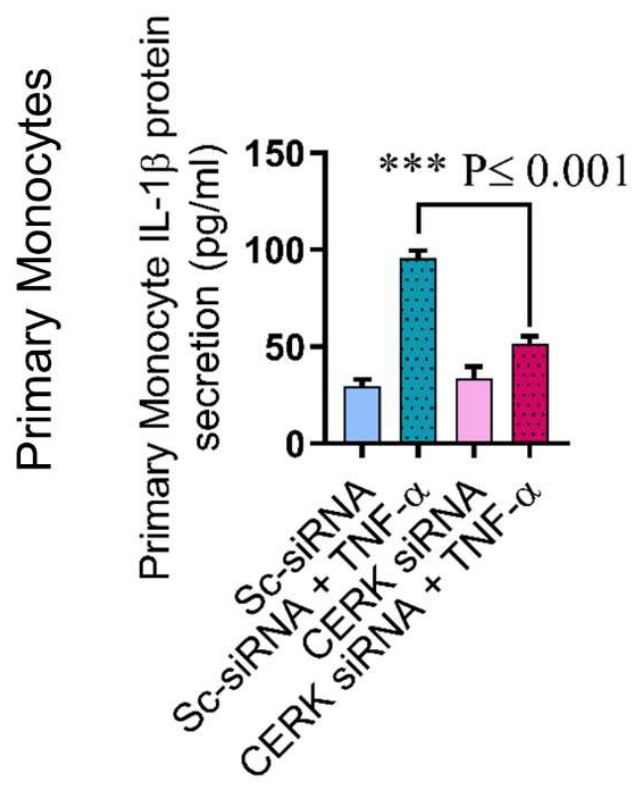

B

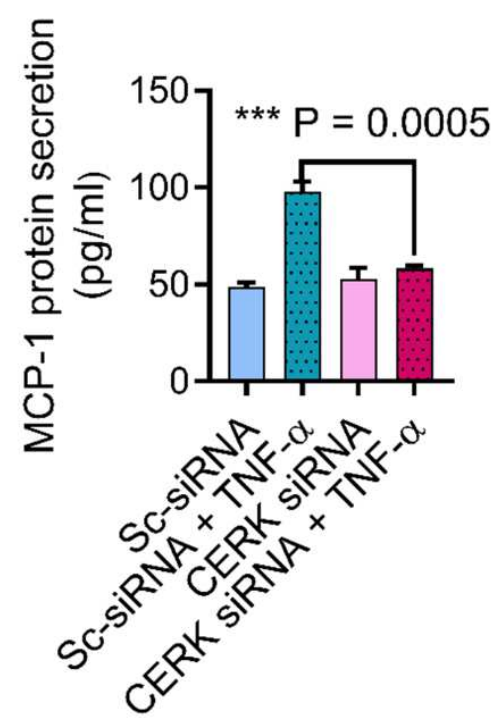

D

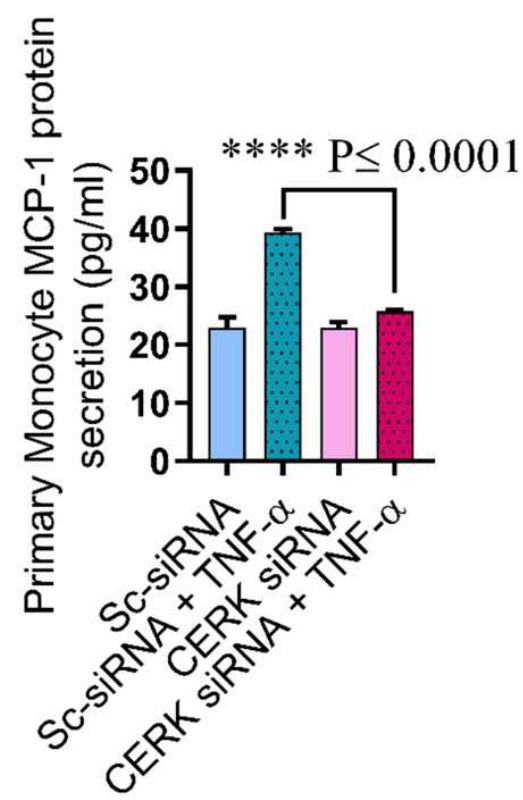


Figure 6
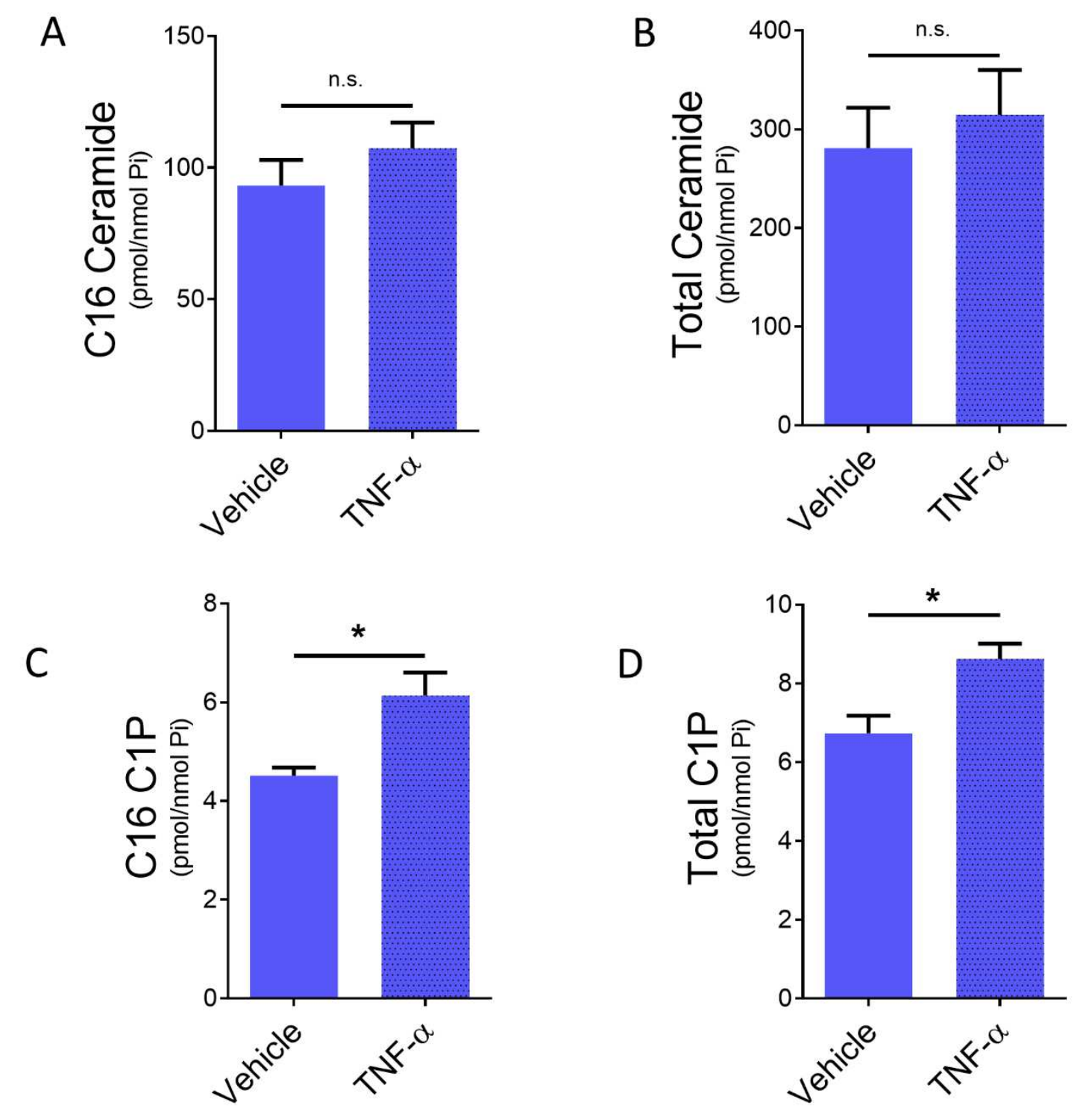
Figure 7

A
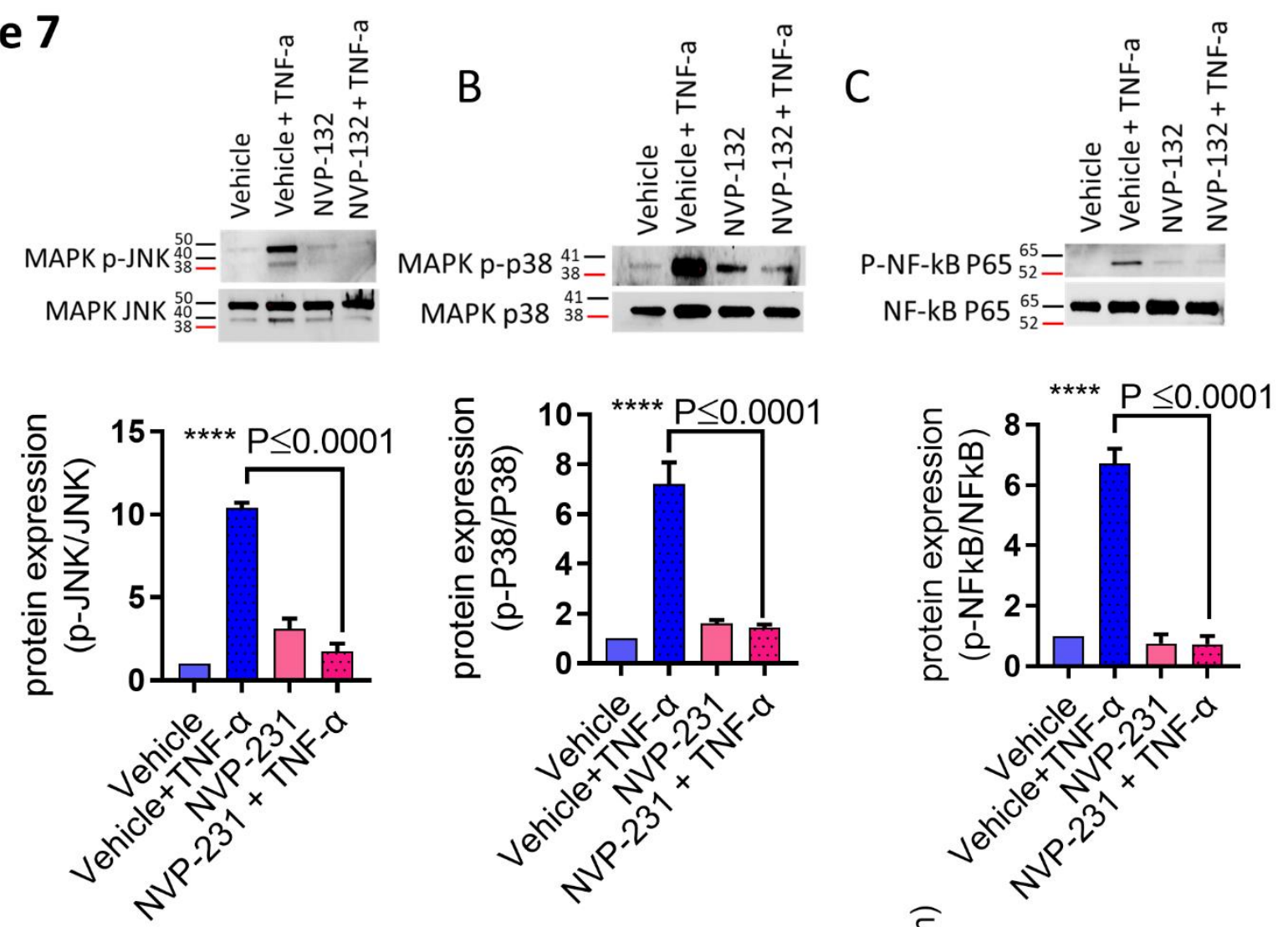

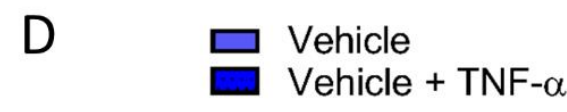
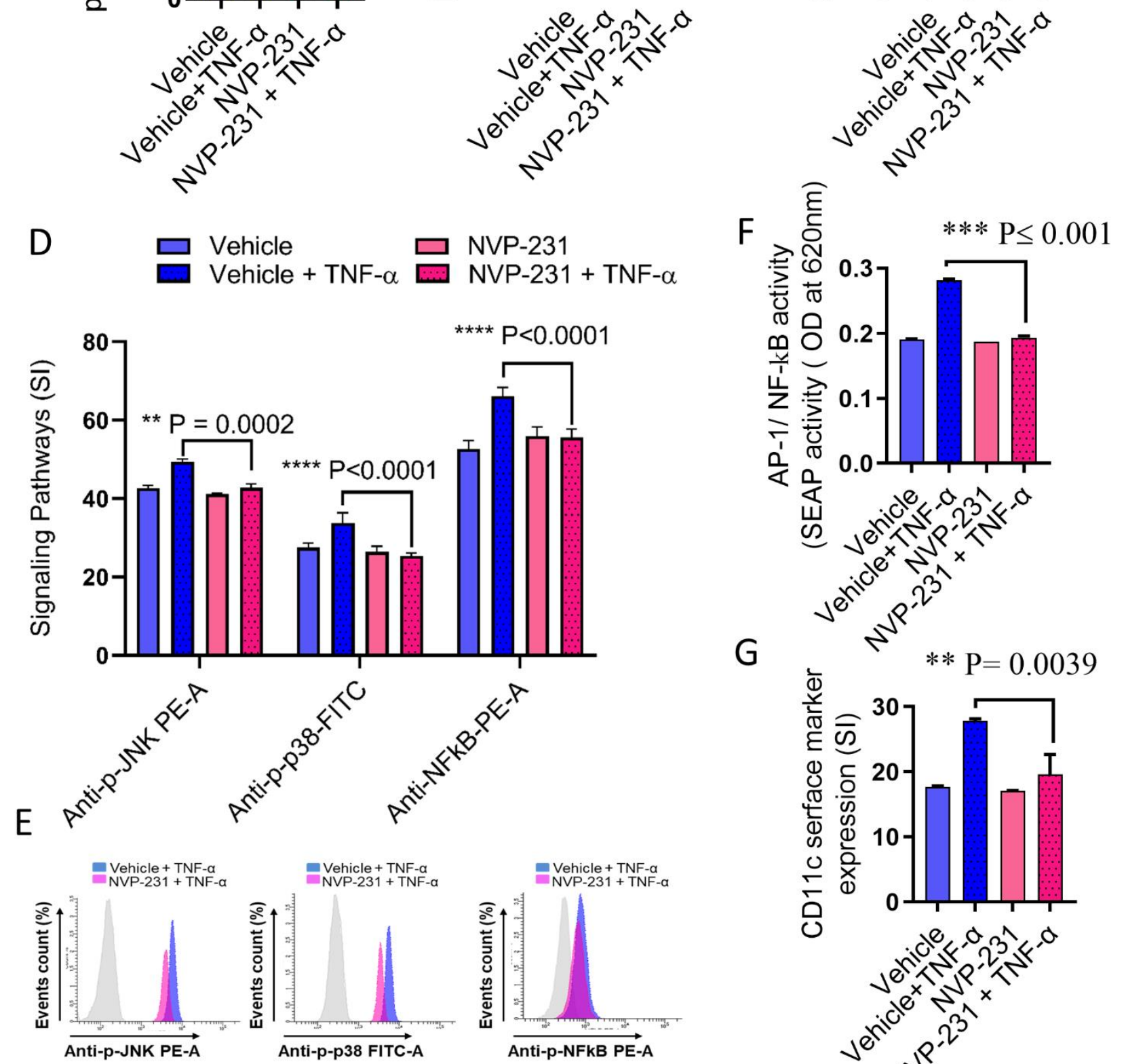

G

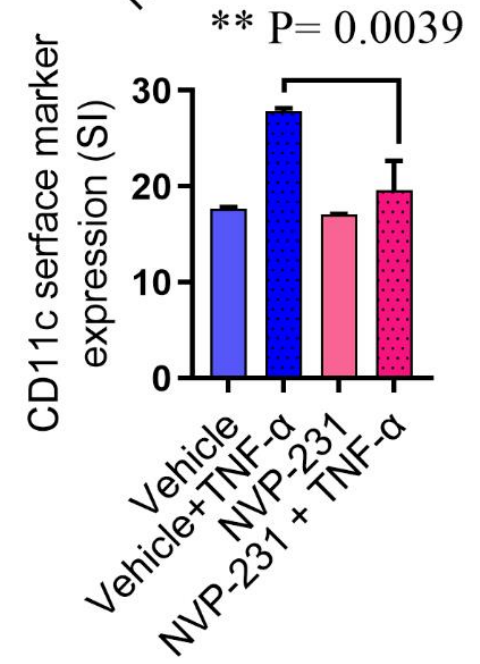


Figure 8

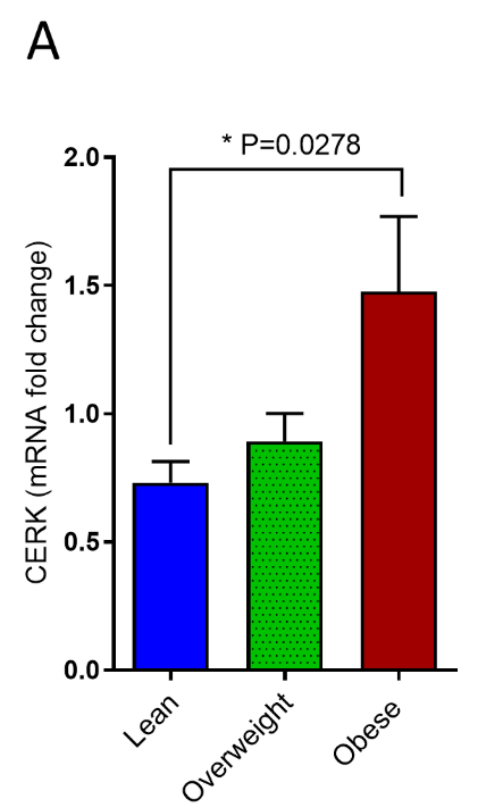

B

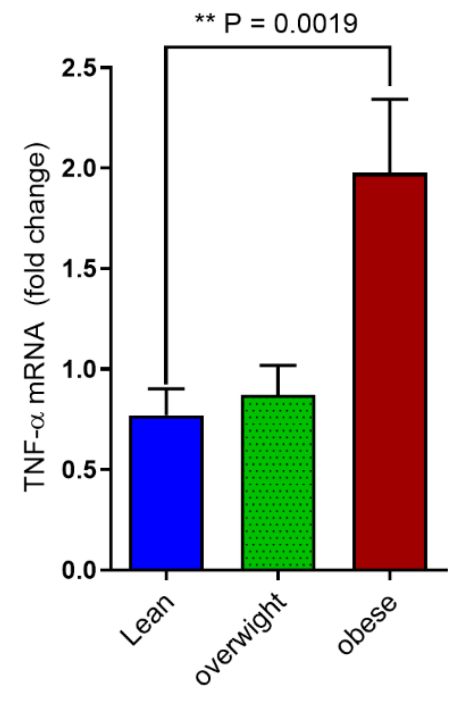

C

$$
P=0.0013, r=0.59
$$

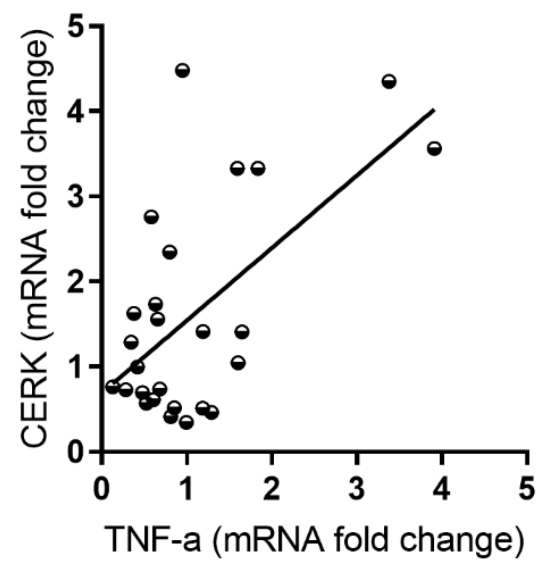




\section{Figure 9}

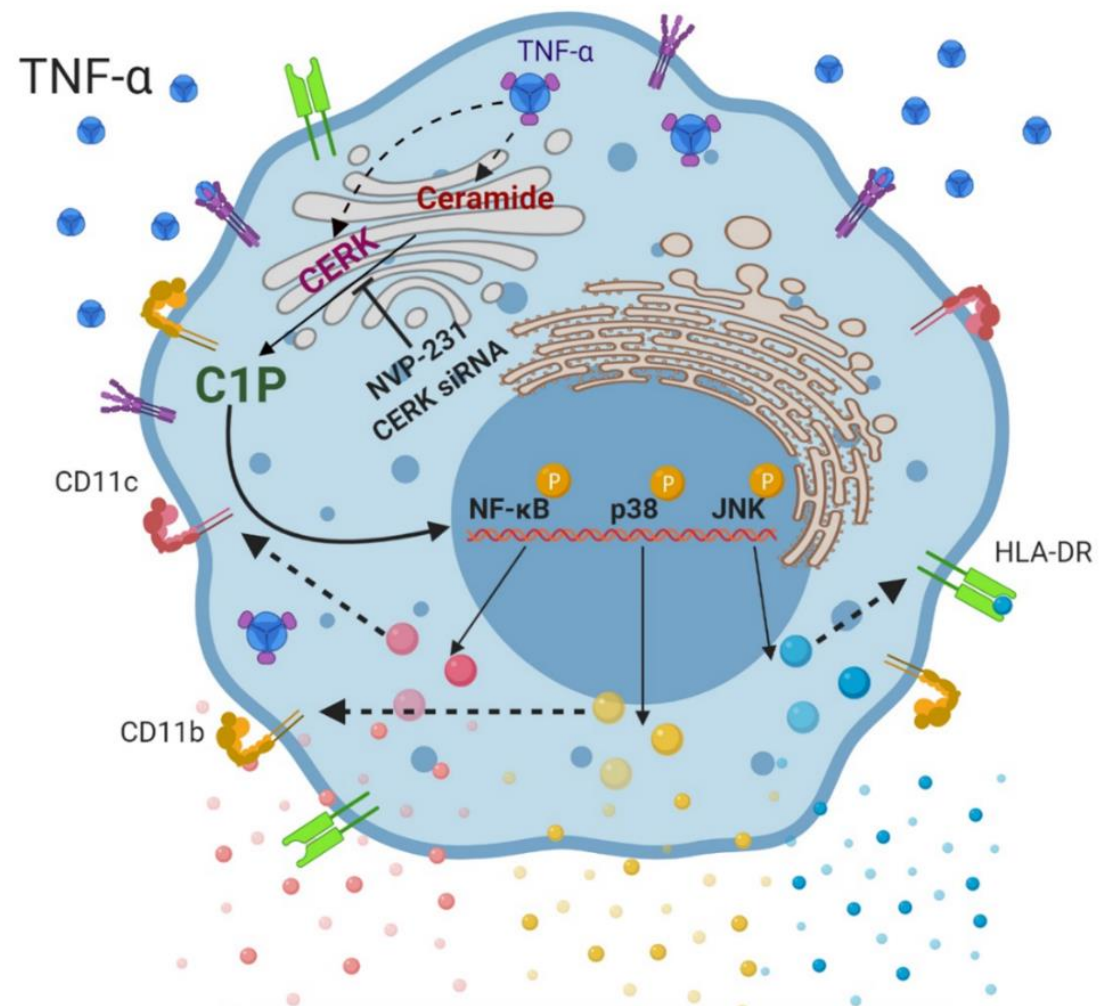

Pro-inflammatory secretion

IL-1 $\beta$

MCP-1 


\section{Figures}

A

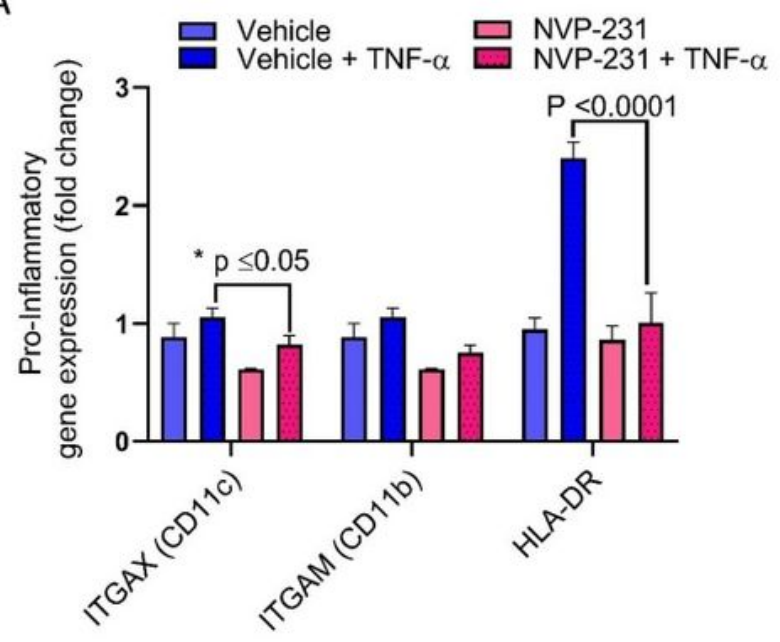

B
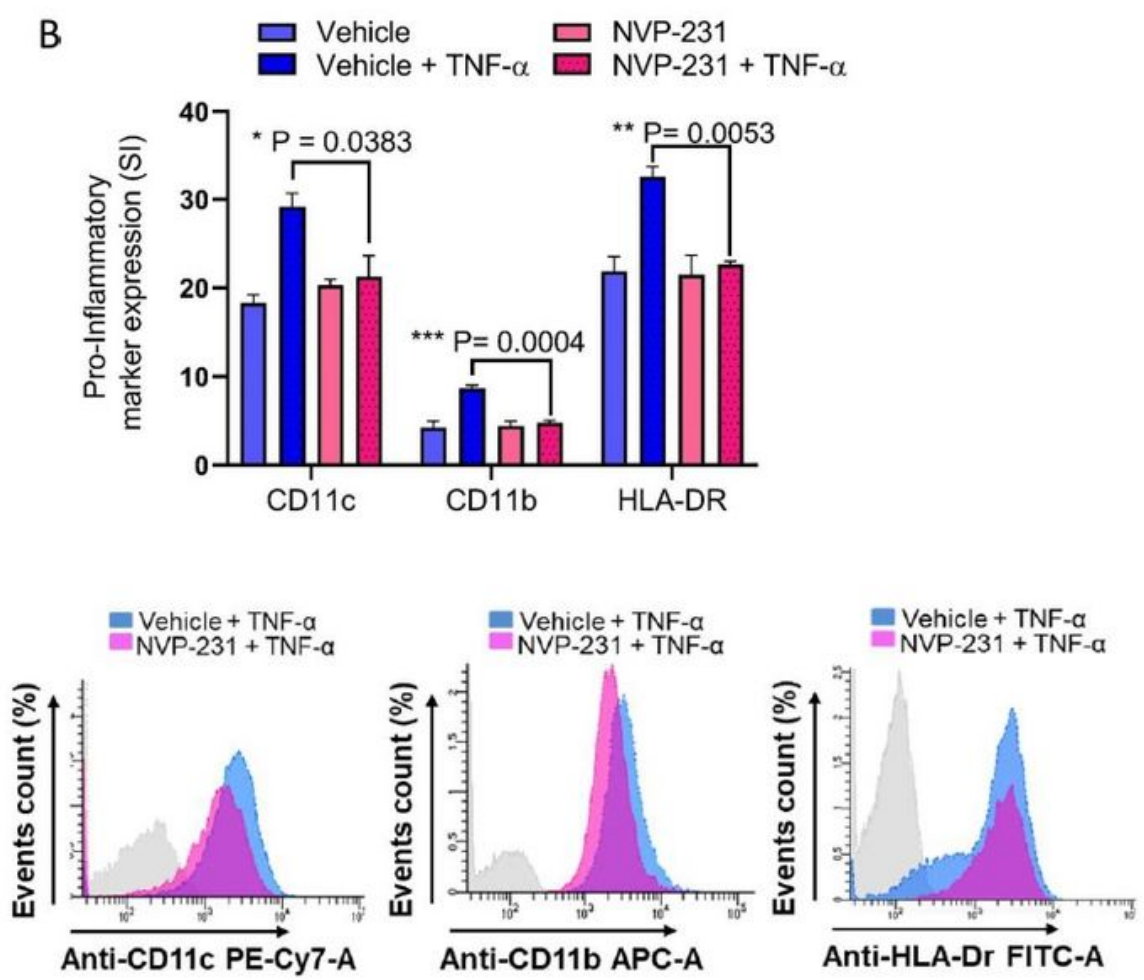

Figure 1

CERK inhibition blocks TNF-a mediated pro-inflammatory changes in THP1. Cells were pretreated with CERK inhibitors (NVP-231: 12nM) or vehicle for 1 hour and then incubated with TNF-a for 2 hours. Cells were harvested and mRNA expression for CD11c, CD11b and HLA-Dr was determined by real time RT-PCR 
(A). After 6 hours treatment with TNF-a, cells were stained with antibodies against CD11c, CD11b ad HLADr along with matched isotype controls. Surface expression were assessed by flow cytometry (B) data are presented as a bar graph of mean staining index, and representative histogram. All data are expressed as mean $\pm \operatorname{SEM}(n \geq 3) .{ }^{*} p \leq 0.05,{ }^{*} p \leq 0.01,{ }^{* *} p \leq 0.001, * * * * p \leq 0.0001$ versus vehicle.
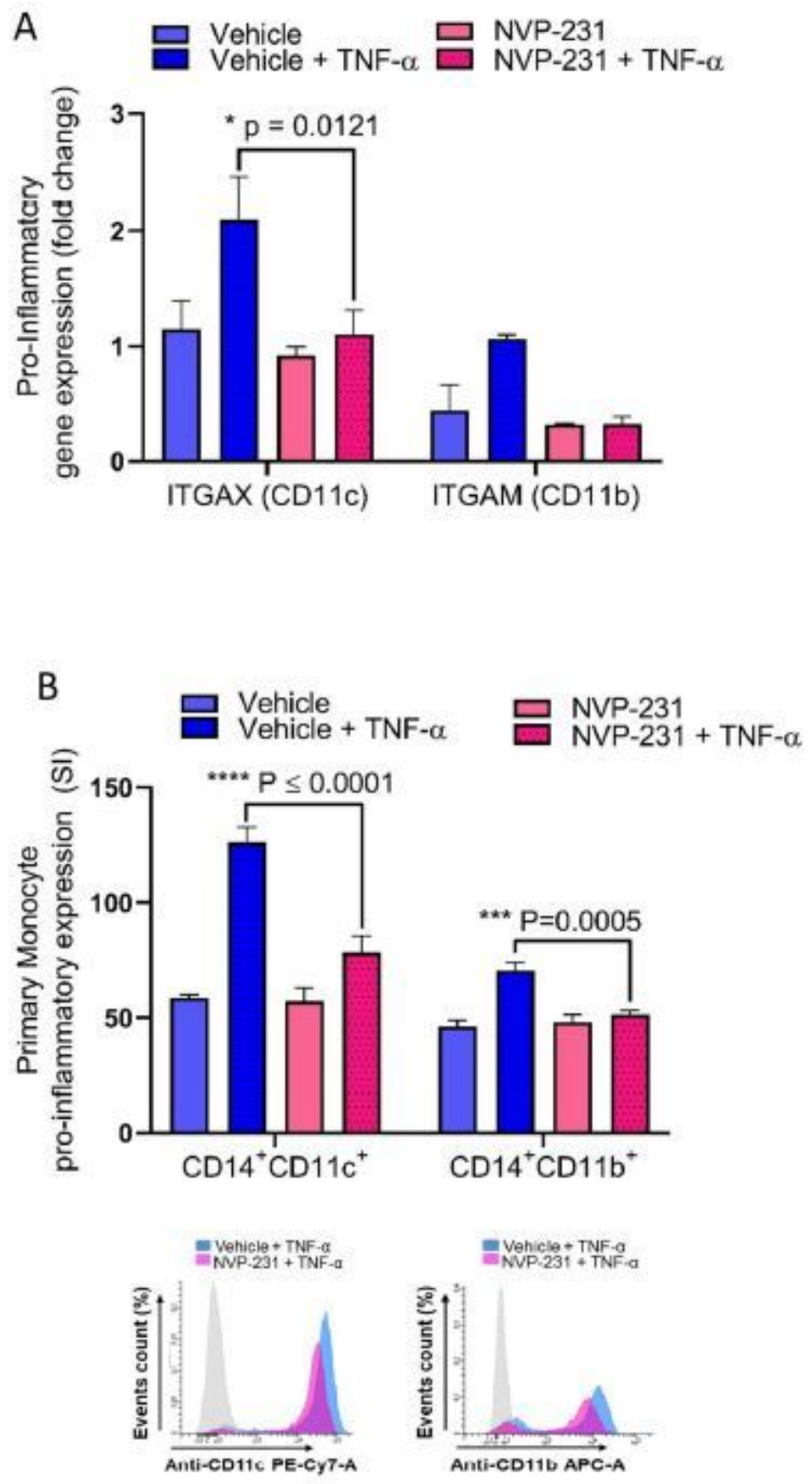

Figure 2

CERK inhibition blocks TNF-a mediated pro-inflammatory changes in primary human monocytes. Human primary monocytes were pretreated with CERK inhibitor (NVP-231: 12nM) or vehicle for 1 hour and then incubated with TNF-a for 2 hours. Cells were harvested and mRNA expression for CD11c and CD11b was 
determined by real time RT-PCR (A). After 6 hours treatment with TNF-a, cells were stained with antibodies against CD11c, CD11b and CD14 along with matched isotype controls. Surface expression of CD14+CD11c+ and CD14+CD11b+ were assessed by flow cytometry (B) data are presented as a bar graph of mean staining index, and representative histogram. All data are expressed as mean \pm SEM ( $n \geq$ 3). ${ }^{*} p \leq 0.05,{ }^{* *} p \leq 0.01,{ }^{* * *} p \leq 0.001,{ }^{* * * *} p \leq 0.0001$ versus vehicle.

A

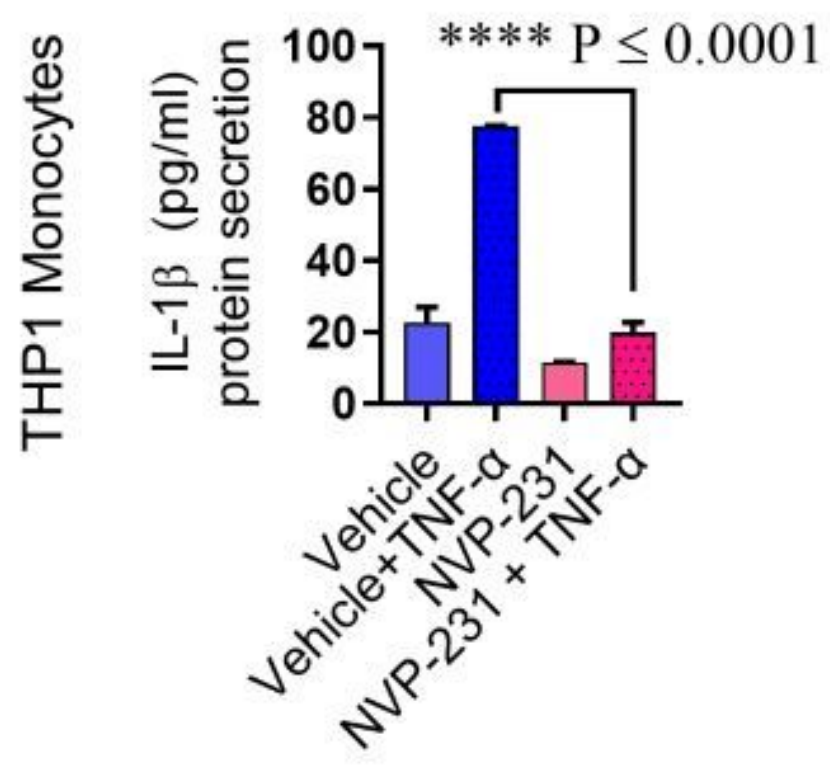

C

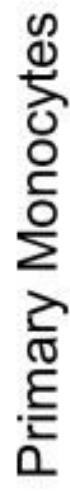

B

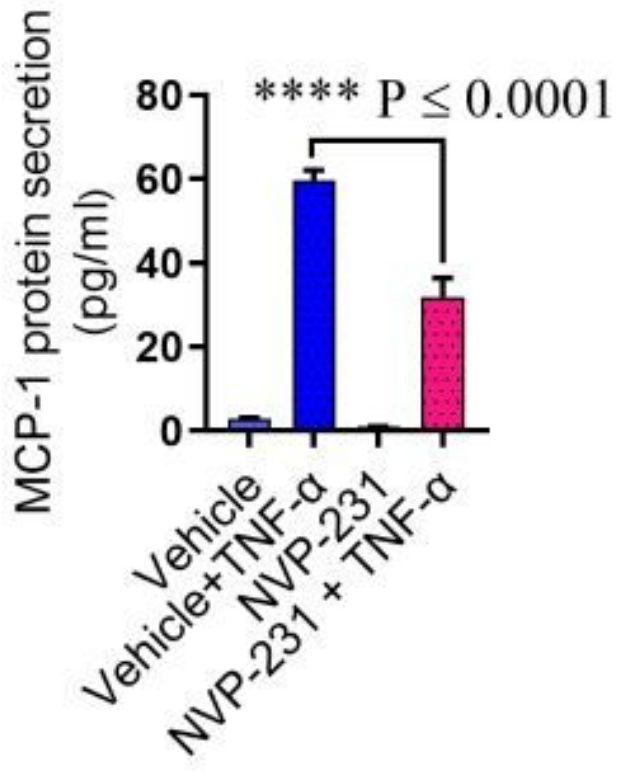

D

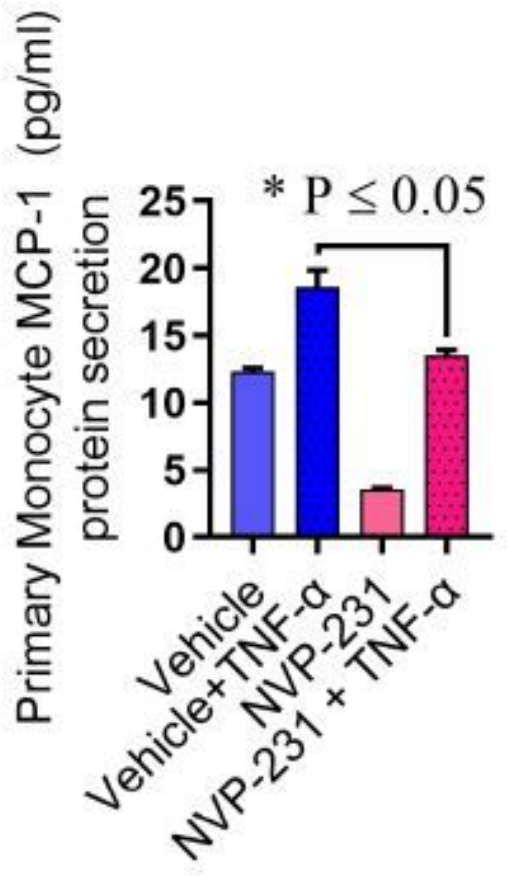

Figure 3 
IL-1b and MCP-1 secreted by TNF- $a$ activated monocytes are suppressed by CERK inhibition. Monocytic cells (primary monocytes, macrophages, THP1 cells) were pretreated with CERK inhibitor (NVP-231: $12 \mathrm{nM}$ ) or vehicle for 1 hour and then incubated cells with absence or presence of TNF-a for 12 hours. Secreted IL-1 $\mathrm{b}$ and MCP-1 protein in culture media was determined by ELISA. IL-1b and MCP1 secreted by THP1 cells $(A$ and $B)$, and primary monocytes $(C$ and $D)$. All data are expressed as mean \pm SEM $(n \geq 3)$. ${ }^{*} p \leq 0.05,{ }^{* \star} p \leq 0.01,{ }^{* \star *} \mathrm{p} \leq 0.001,{ }^{* \star *} \mathrm{p} \leq 0.0001$ versus vehicle.

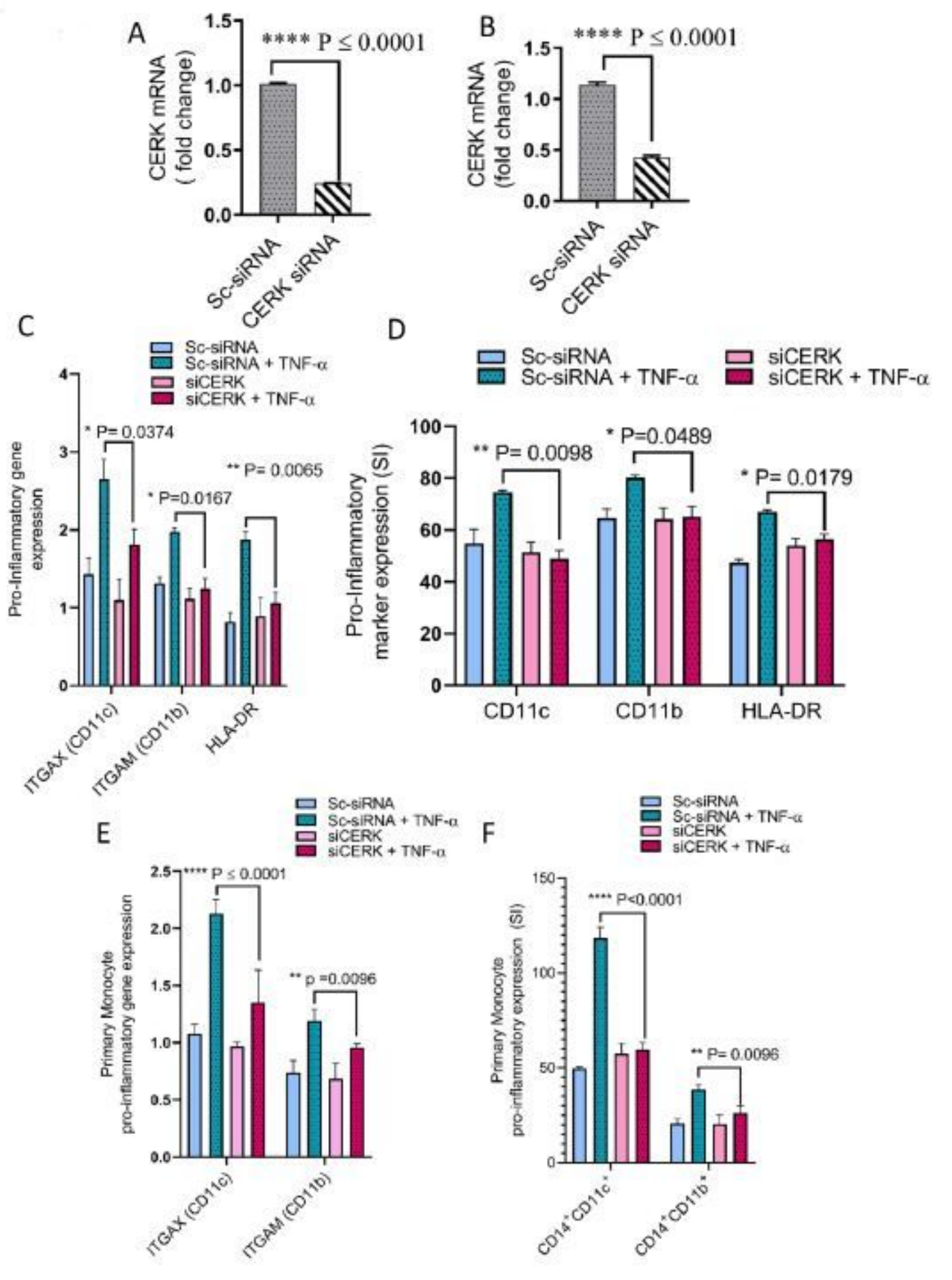

Figure 4 
TNF-a mediated pro-inflammatory monocytic responses require CERK. THP1 monocytes and Primary monocytes were transfected with scramble-siRNA (negative control; NC) or CERK siRNA and incubated for 36 hours. Real-time PCR was performed to measure (A) CERK expression in THP1 monocytic cells and (B) primary monocytes. CERK deficient THP1 cells were treated with TNF- $a$ and vehicle. Cells were stained with antibodies against CD11c, CD11b and HLA-Dr along with matched isotypes and were subjected to flow cytometry analysis. Flow cytometry data are presented as a bar graph of mean staining index of the inflammatory markers (C). CD11c, CD11b and HLA-Dr were determined by real time RT-PCR (D). primary monocyte surface expression of $C D 14+C D 11 c+$ and $C D 14+C D 11 b+$ was determined by flow cytometry along with matched isotypes control (E) CD11 $\mathrm{c}$ and $\mathrm{CD} 11 \mathrm{~b}$ mRNA were determined by real time RT-PCR (F). All data are expressed as mean \pm SEM $(n \geq 3)$. ${ }^{\star} p \leq 0.05,{ }^{* \star} p \leq 0.01,{ }^{* \star *} p \leq 0.001,{ }^{* \star \star *} p \leq 0.0001$ versus vehicle. 
A

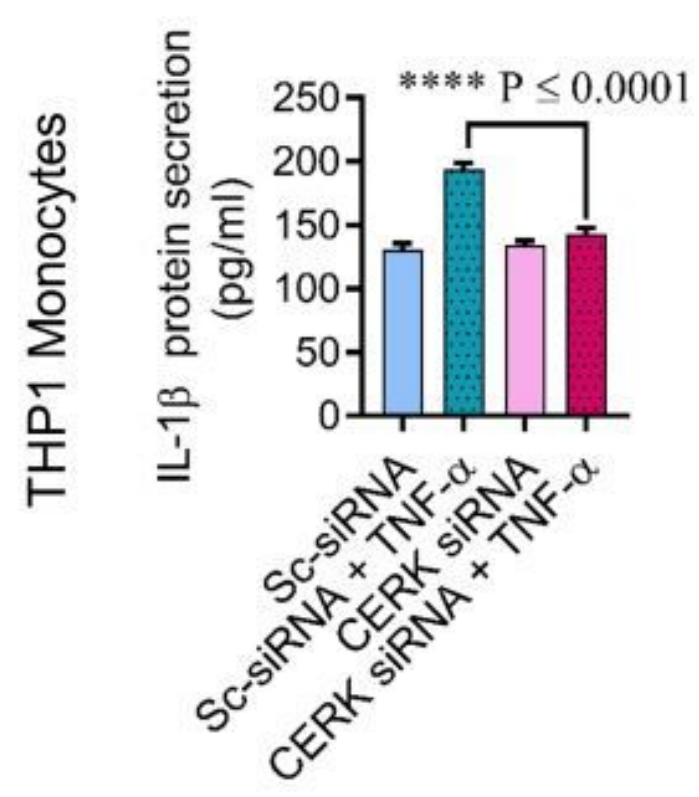

C

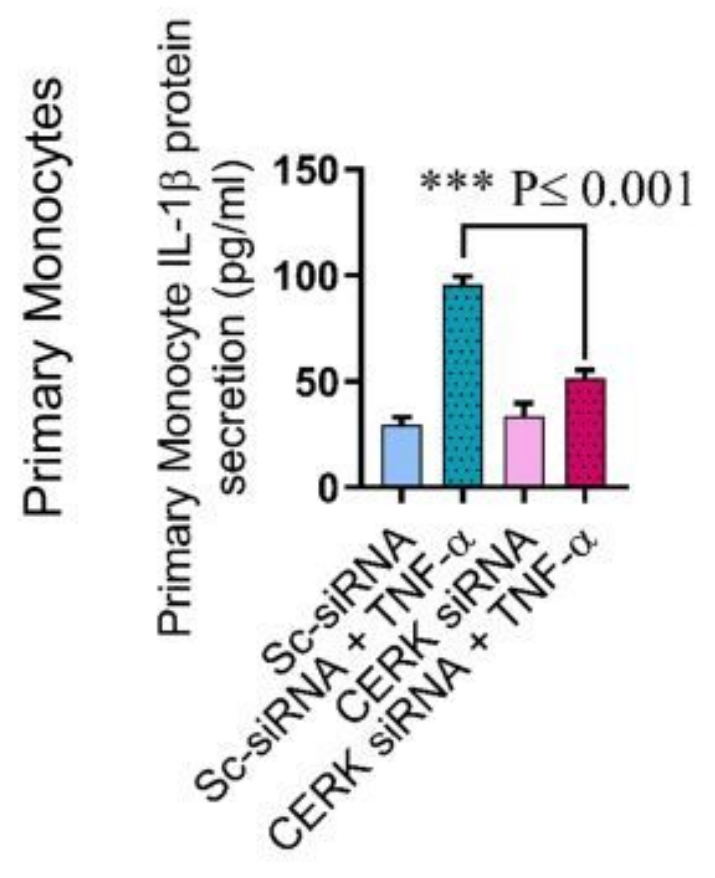

B
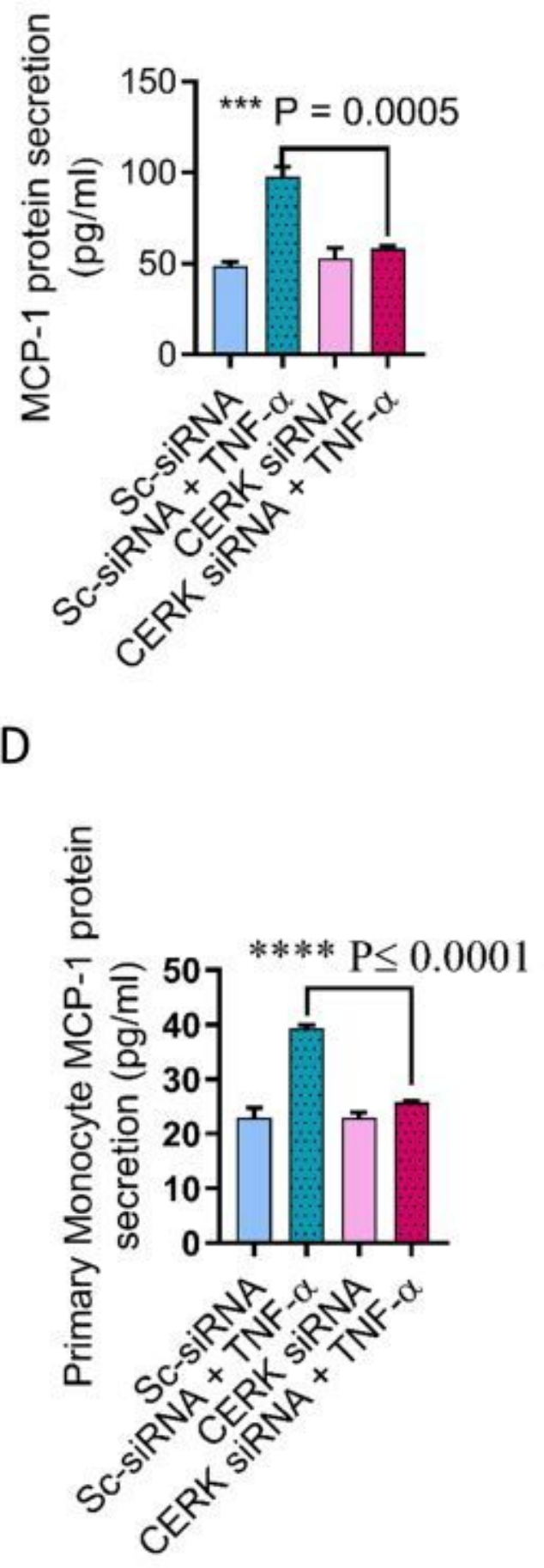

\section{Figure 5}

CERK deficiency attenuates IL-1b and MCP-1 secretion induced by TNF- $a$ activated monocytes. THP1 monocytes and Primary monocytes were transfected with scramble-siRNA (negative control; NC) or CERK siRNA and incubated for 36 hours. CERK deficient THP1 and primary monocytes were treated with TNF-a for 12 hours. Secreted IL-1b and MCP-1 protein in culture media was determined by ELISA. IL-1b and 
MCP1 secreted by THP1 cells (A and B), and primary monocytes (C and D). All data are expressed as mean \pm SEM $(n \geq 3) .{ }^{*} p \leq 0.05,{ }^{* \star} p \leq 0.01,{ }^{* \star *} p \leq 0.001,{ }^{* \star \star *} p \leq 0.0001$ versus vehicle.
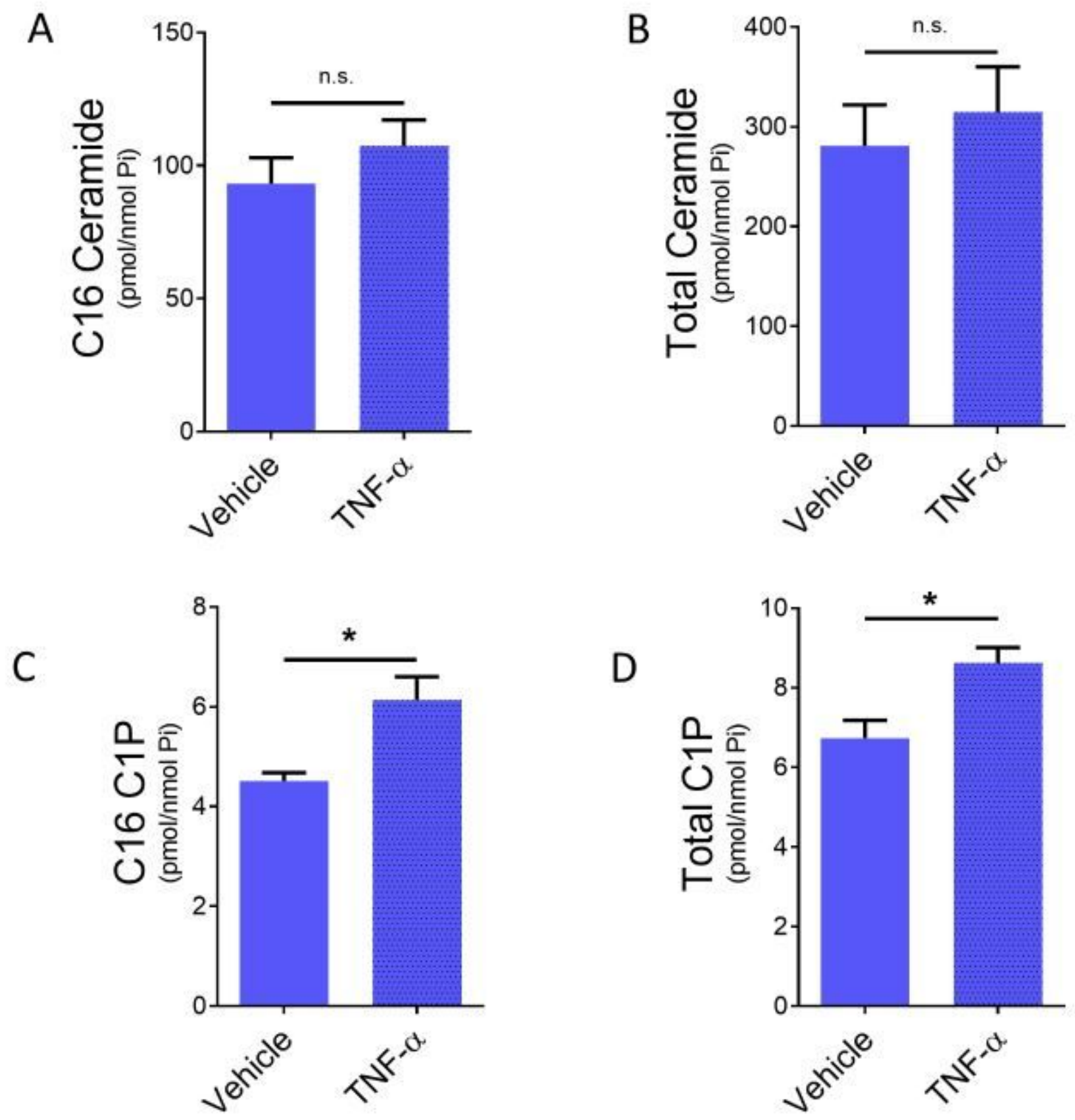

Figure 6

TNF-a induces ceramides in monocytic cells THP-1 monocytes were treated with vehicle or TNF-a for 12 hours. Cellular lipid levels were analyzed A) C16 ceramide, B) total ceramides, C) C16 C1P, D) total C1P by ESI/MS/MS in the Stony Brook University Lipidomics Shared Resource Core and normalized to total lipid phosphate (Pi). Data represent mean $\pm S E M, n=4,{ }^{*} p<0.05$ as compared to Vehicle treatment. 
A
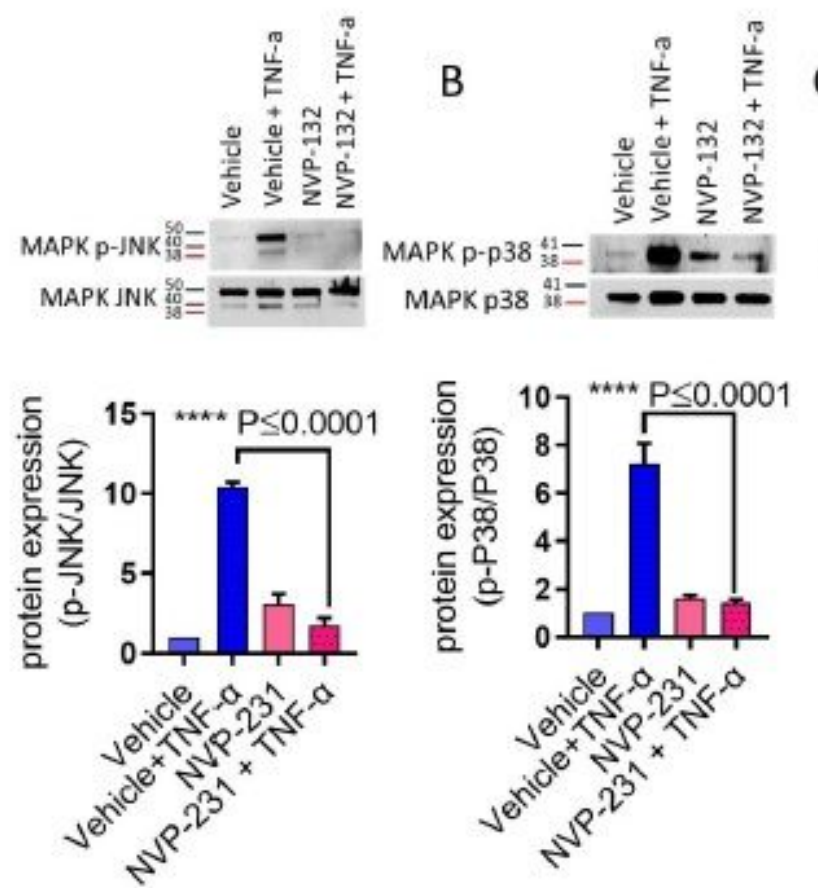

D

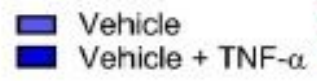

口 NVP-231

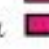
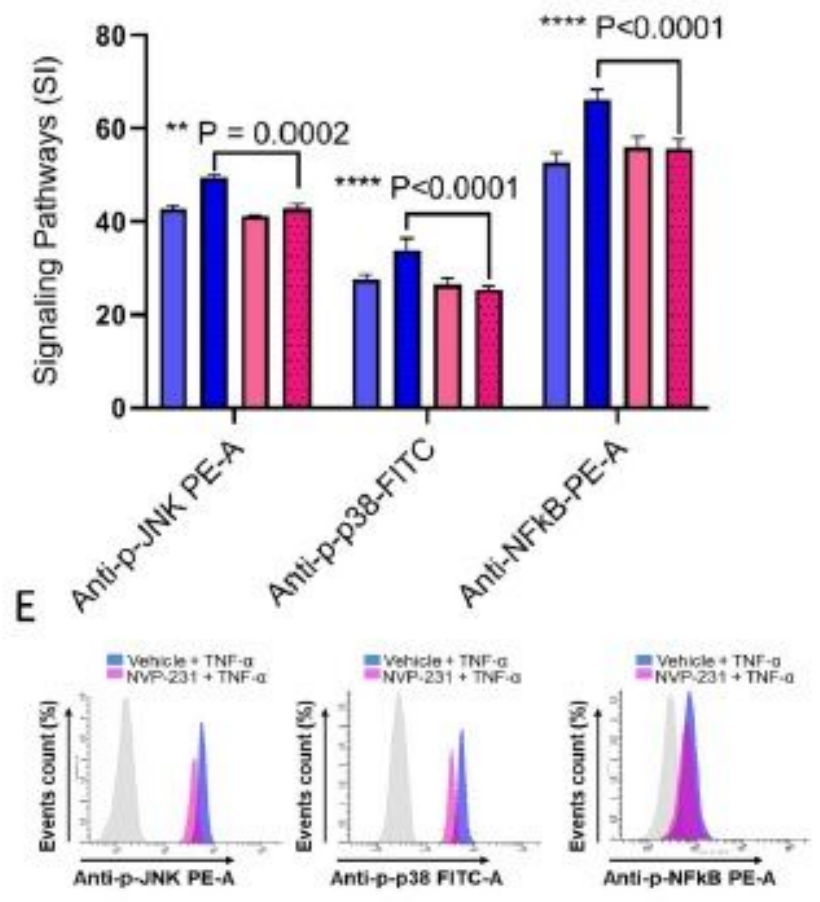
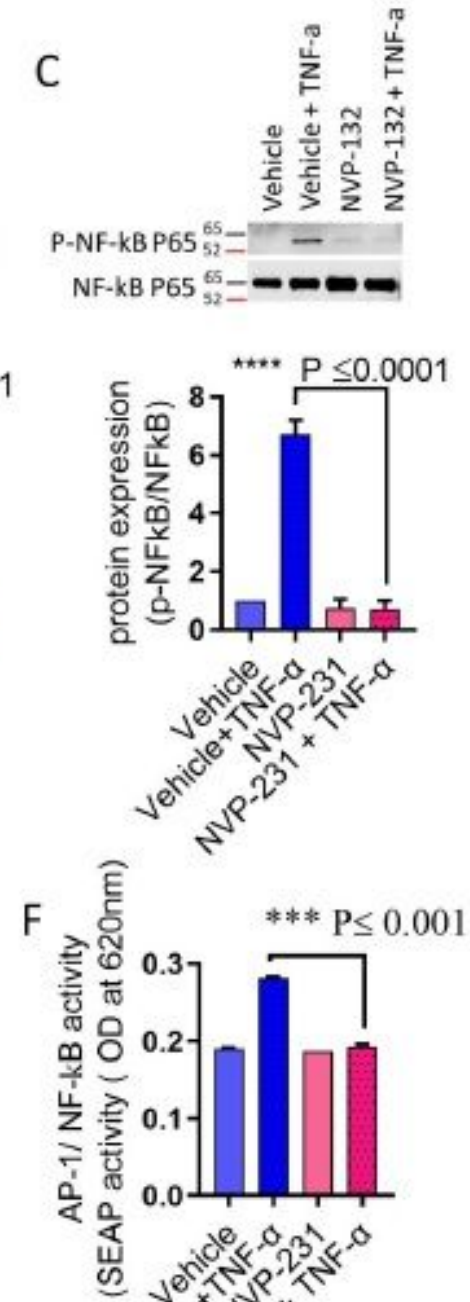

G
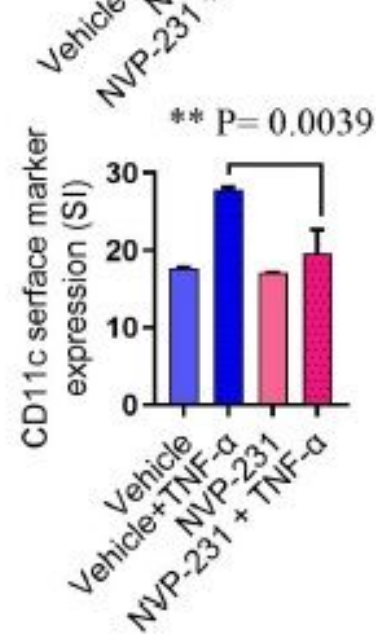

\section{Figure 7}

Inhibition of CERK affects TNF-a activated MAPK and NF-KB signaling pathways in THP1 cells. THP1 Monocytic cells were pretreated with CERK inhibitor (NVP-231: 12nM) and then incubated with TNF-a . Cell lysates were prepared as described in material and methods. Samples were run on denaturing gels. Immuno-reactive bands were developed using an Amersham ECL Plus Westren Blotting Detection System (GE Healthcare, Chicago, IL, USA) and visualized by Molecular Imager ${ }^{\circledR}$ ChemiDoc $^{\text {TM }}$ MP Imaging Systems 
(Bio-Rad Laboratories, Hercules, CA, USA). (A) Phosphorylated proteins of SPAK/JNK, (B) p38 and (C) NF$\mathrm{kB}$ are shown in the upper panels with the lower panel representing respective total proteins. The phosphorylation intensity was quantified by using Image Lab software (version 6.0.1, Bio-Rad, Hercules, CA, USA) and are presented in bar graphs in arbitrary unit of corrected protein expression. Signaling proteins were also determined by Flow cytometry. Cell were immediately fixed and permeabilize for 20 min at $4 \mathrm{oC}$ then stained to visualize for JNK, p38 and NF-KB phosphorylation. Flow cytometry data are presented as a bar graph of mean staining index $(\mathrm{SI})$ as well as and representative histogram ( $\mathrm{D}$ and $\mathrm{E})$. Bar graphs depict mean values \pm SEM of staining intensity (SI). $P<0.05$ was considered as statistically significant $\left({ }^{\star} P \leq 0.05 ;{ }^{* \star} P \leq 0.01,{ }^{\star *} \times P \leq 0.001,{ }^{* \star \star \star} P \leq 0.0001\right)$. The data in all Figures are representative of three independent experiments. NF-KB/AP-1 reporter monocytic cells were pretreated with CERK inhibitor (NVP-231: 12nM) or vehicle for 1 hour and then incubated with TNF-a for 12 hours. Cell culture media were assayed for SEAP reporter activity (degree of NF-KB activation) (F). Reporter cells were also tested for expression of CD11c (G).
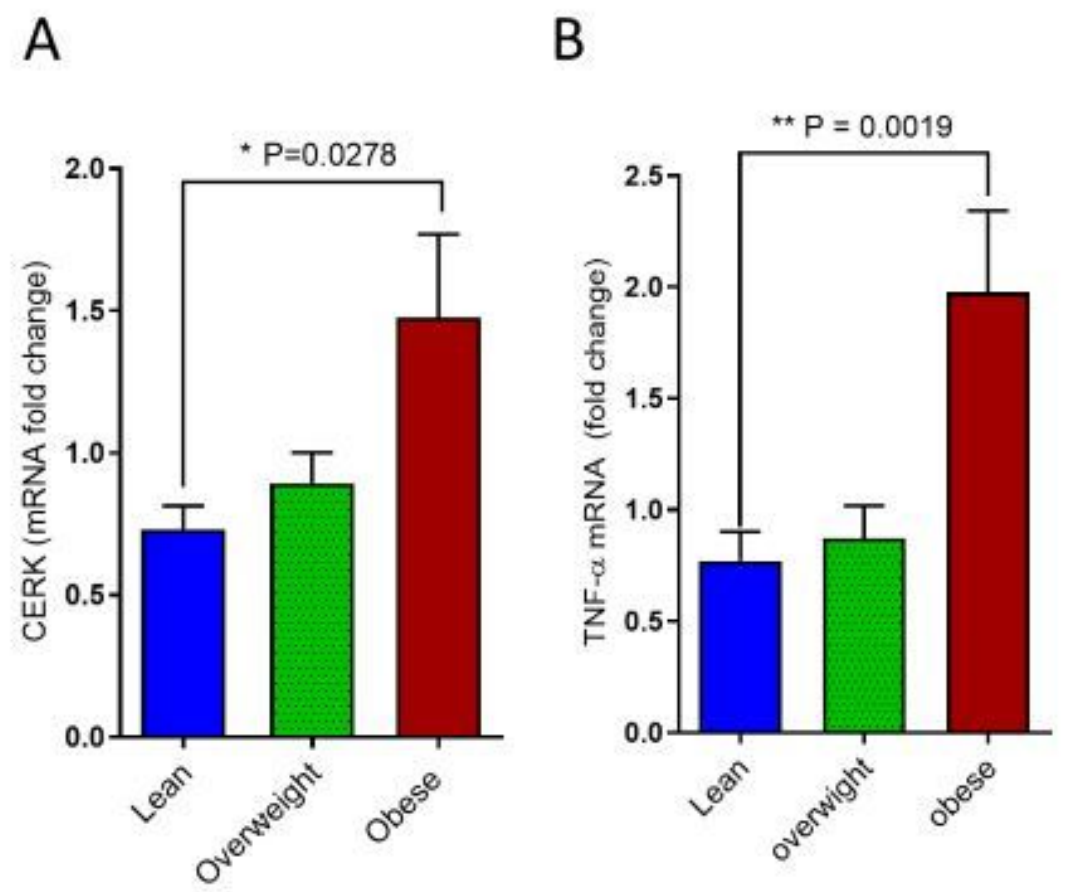

C

$$
P=0.0013, r=0.59
$$

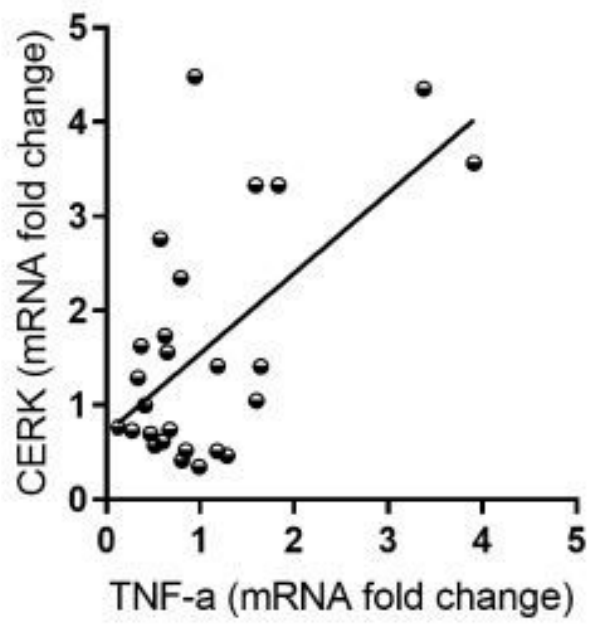

\section{Figure 8}

Association of elevated TNF-a with CERK levels in obese human PBMCs. PBMCs were isolated from human blood samples obtained from lean $(n=13)$, overweight $(n=14)$ and obese $(n=13)$ individuals. mRNA of CERK and TNF-a were detected by real time RT-PCR and represented as fold change over controls (A and B). Pearson's correlation coefficient ( $r$ ) conducted between CERK and TNF- $a(C)$. 


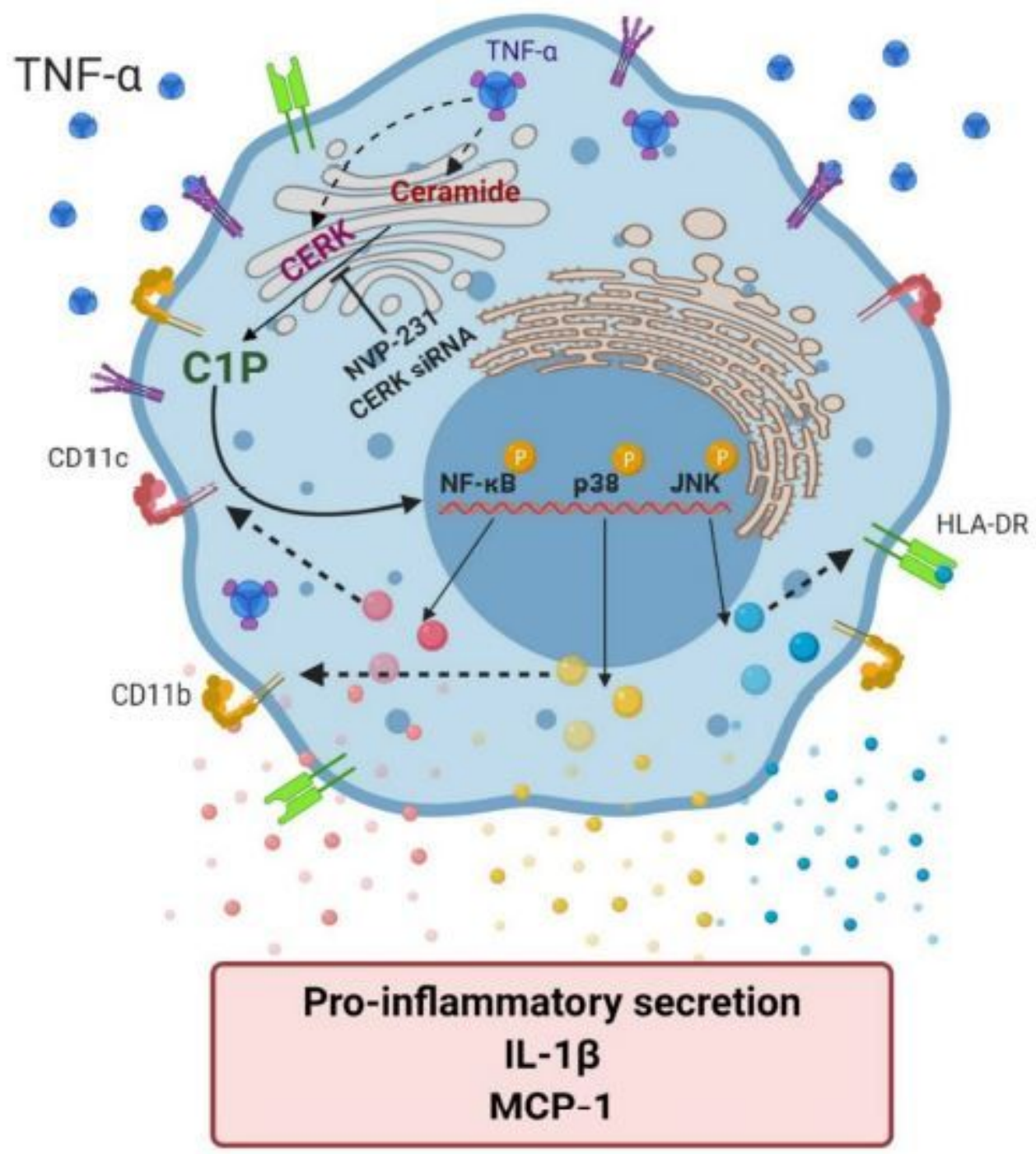

Figure 9

Schematic illustration summarizing the involvement of CERK in TNF-a mediated inflammatory responses in human monocytic cells. Figure is created by BioRender.com.

\section{Supplementary Files}

This is a list of supplementary files associated with this preprint. Click to download.

- SupplementaryInfoFile.pdf 